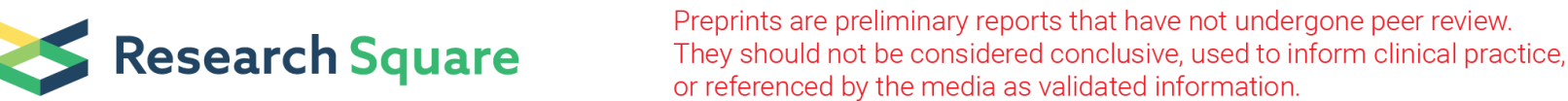

\section{The Physics of Detonation Chemistry: A Radical Theory in Predicting the Deflagration to Detonation Transition}

V R Sanal Kumar ( $\sim$ vr_sanalkumar@yahoo.co.in )

Indian Space Research Organisation https://orcid.org/0000-0002-5643-7223

Nichith Chandrasekaran

Indian Institute of Science Bangalore

Vigneshwaran Sankar

Indian Institute of Science Bangalore

Ajith Sukumaran

Kumaraguru College of Technology

Sivabalan Mani

Georgia Institute of Technology

Tharikaa Ramesh kumar

Auburn University

Sathyan Padmanabhan

University of Arizona

Roshan Vignesh Baskaran

Kumaraguru College of Technology

Vishnu Natarajan

Pusan National University

Hema Sai Nagaraju Doddi

Embry-Riddle Aeronautical University

Mohammed Niyasdeen Nejaamtheen

King Fahd University of Petroleum and Minerals

Sulthan Ariff Rahman Mohamed Rafic

Kumaraguru College of Technology

Roshan Vignesh Baskaran

Kumaraguru College of Technology

Pavithra Murugesh

Kumaraguru College of Technology

Amrith Mariappan

Kumaraguru College of Technology

Thianesh U. K. 
Kumaraguru College of Technology, Coimbatore

\section{Anand moorthi}

Kumaraguru College of Technology

\section{Mohan Elumalai}

Kumaraguru College of Technology

\section{Bharath R.S.}

Indian Institute of Science Bangalore

\section{Charlie Oommen}

Indian Institute of Science Bangalore

\section{Pradeep Kumar Radhakrishnan}

GITAM University

\section{Shiv Kumar Choudhary}

All India Institute of Medical Sciences

\section{Article}

Keywords: Deflagration-to-detonation-transition (DDT), detonation, nanofluid flow system design, hemorrhagic-stroke, Sanal flow choking, streamtube-flow-choking, Chemical rocket.

Posted Date: October 8th, 2020

DOI: https://doi.org/10.21203/rs.3.rs-86415/v1

License: (c) (1) This work is licensed under a Creative Commons Attribution 4.0 International License. Read Full License 


\section{Abstract}

The theoretical finding of the Sanal-flow-choking [PMCID: PMC7267099] is a methodological advancement in predicting the deflagration-to-detonation-transition (DDT) in the real-world-fluid flows (continuum/non-continuum) with credibility.[1,2] Herein, we provide a proof of the concept of the Sanalflow-choking and streamtube-flow-choking causing DDT in wall-bounded and free-external flows. Once the streamlines compacted, the considerable pressure difference attains inside the streamtube and the flow gets accelerated to the constricted region for satisfying the continuity condition set by the conservation law of nature. If the shape of the streamtube in the internal/external flow is similar to the convergent-divergent (CD) duct the phenomenon of the Sanal-flow-choking and supersonic flow development occurs at a critical-total-to-static pressure ratio (CPR) in yocto to yotta scale systems and beyond, which leads to shock wave generation or detonation as the case may me. At the lower critical detonation or hemorrhage index, the CPR of the reacting flow and the critical blood-pressure-ratio (BPR) of the subjects (human being/animal) are unique functions of the heat-capacity-ratio (HCR) of the evolved gas in the CD duct. In silico results are presented herein to establish the proof of the concept of the Sanal-flow-choking and streamtube-flow-choking causing shock-wave/detonation in diabatic flow systems and asymptomatic-hemorrhagic-stroke in biological systems. The physics of detonation chemistry presented herein sheds light for exploring supernova explosions.[107]

\section{Introduction}

Although the underlying knowledge in advanced science of real-world flows (continuum / non-continuum) with the multi-disciplinary focus has been evolved over the centuries there are still many unresolved problems due to the lack of fundamental understanding of physics and chemistry of diabatic fluid flows (flow involves transfer of heat). ${ }^{[1]}$ Such problems of urgency to the scientific communities are the prediction and attenuation of detonation in reacting fluid flow systems and that of asymptomatic stroke (AS) in the human circulatory system (HCS). Note that the deflagration to detonation transition (DDT) in reacting fluid flow systems and the creeping flow to asymptomatic hemorrhagic stroke(AHS) in biological systems could happen due to the consequence of the Sanal flow choking. ${ }^{[1-9]}$ Over the decades several in vitro and in silico studies were reported on DDT in various energy systems from yocto to yotta scales but there were no authentic answers on the fundamental cause of DDT in real-world fluid flow systems. ${ }^{[10-20]}$ Modeling and simulation of nanoscale fluid flow is truly intricate, because in the contrary to milli-scale or macroscale fluid flow, the governing-equations capturing exact flow physics and chemistry are not well delineated. ${ }^{[21-26]}$ Hence, even if the in silico method is well suited for the solution of considered problem, in vitro methods in nanoscale are having inherent inaccuracy for generating benchmark data for in silico code verification. Therefore, one should rely up on the exact solution for generating benchmark data for solving unresolved problems carried forward over the centuries with credibility. Such models should scrupulously satisfy the conservation laws as imposed by our nature. Therefore, the Sanal flow choking models ${ }^{[1]}$ should be invoked for in silico model validation, verification 
and calibration before featuring fluid flow characteristics of yocto to yotta scale diabatic fluid flow systems and beyond with reliability.

Of late, small scale systems have got significant attention in the industry because mostly micro/nanoelectromechanical systems (MEMS/NEMS) are based on the fluid motion. ${ }^{[21]}$ This is particularly true in the nano medicine for drug discovery and nano/micro thrusters for aerospace systems design. Obviously, the nano scale fluid flow system development in microgravity aerospace application is a challenging research topic. Furthermore, such systems in atmospheric conditions applicable to physical, chemical, and biological sciences are also challenging areas for research due to the pragmatic difficulties to perform in vitro and in silico studies and in addition the lack of closed-form analytical models for benchmarking. Various researchers reported through in vitro and molecular dynamics simulations that the surface friction compared to the fluid flow is very low for carbon nanotubes (CNT). ${ }^{[26-29]}$ The fact is that the reported results were not supported with benchmark data generated from any exact solution for meeting all the conservation laws of nature.

Qi-Long Yan et al. ${ }^{[30]}$ reported (2016) that encapsulation of energetic molecules into CNTs is extremely challenging and still demanding additional analytical and in vitro studies to understand its sensitivity and performances ${ }^{[31-34]}$ having with highly sensitive energetic material (EMs). Gunpowder, a firearm propellant, invented in ancient China is believed as the earliest energetic material, ${ }^{[30]}$ which generally does not detonate but rather deflagrates. The deflagration and detonation properties of black powder however differ significantly from new generation high energetic solid propellants ${ }^{[35,36]}$ and there are no authentic predictive models available as on the date to forecast these properties at nanoscale. Therefore, in silico simulation of DDT in the real-world nanofluid flow system is the need of the 21st century; and it must be verified with an exact solution for a credible decision making. ${ }^{[36-38]}$ Admittedly, there are no literature available on in silico simulation of DDT in milli-scale or nanoscale systems having port with the sudden expansion/divergence region. ${ }^{[39-45]}$

The Sanal flow choking, a compressible fluid flow effect, is a radical theory in advanced science of real-world fluid flow systems, ${ }^{[1]}$ which is capable to provide solutions to many unanswered research questions in the continuum and non-continuum fluid flows moved ahead over the centuries. ${ }^{[46-62]}$ Note that the non-continuum or nanoscale fluid flows obey all conservation laws of nature. Indeed, all fluids available in our nature are compressible. ${ }^{[1]}$ In the case of nanoscale fluid flows, when pressure increases the Knudsen number reduces causing the compressible viscous flow effect due to the decrease in the average mean free path heading to zero-slip wall boundary condition. All these deliberations corroborate that the Sanal flow choking model puts a focal role in interdisciplinary science for performing in-silico experiments with credibility in the continuum and non-continuum fluid flows in yocto to yotta scale systems. Certainly, at the Sanal flow choking condition for diabatic flows (flow involves transfer of heat) all conservation laws of nature are contented. Any fluid flow solver calibrated with the Sanal flow choking condition of diabatic flow could be capable to predict a priori the risk of DDT in chemical energy systems and AHS in biological systems. ${ }^{[1]}$ It could be achieved by predicting the lower critical detonation index 
(LCDI) and the lower critical hemorrhage index ( $\mathrm{LCHI}$ ) as the case may be. It is pertinent to note that both the LCDI and the LCHI are representing the critical pressure ratio of the respective systems. These indexes are regulated by the heat-capacity-ratio (HCR) of the evolved gas with the lowest HCR.

In this article we are primarily focusing on analytical modeling and in silico simulation of a diabatic fluid flow system aiming to demonstrate the Sanal flow choking, streamtube flow choking, shock wave generation and pressure overshoot for proving the concept of the occurrence of DDT in a classical straight-tube ending with a divergent port geometry at the subsonic inflow condition. This physical situation is analogous to the creeping flow to the choked flow condition in an artery with the divergent/bifurcation/vasospasam region causing AHS (see Figure 1(a-h) as the central illustration). Herein, we made an effort to correlate the radical theory of the Sanal flow choking in the human circulatory system (HCS) because blood is a compressible fluid. ${ }^{[1]}$ Furthermore, in vitro study shows (see Fig.2) that carbon dioxide $\left(\mathrm{CO}_{2}\right)$ gas is predominant in fresh-blood samples of the healthy human-being than Guinea-pig at a temperature range of $37-40^{\circ} \mathrm{C}\left(98.6-104^{\circ} \mathrm{F}\right)$, which increases the risk of flowchoking leading to AHS. It is an admitted fact that the Sanal flow choking steers to the shock-wave generation in viscoelastic tubes with vasospasm (see the attached in vitro results as movie S1 and S2) like blood vessels, which create memory effect leading to AHS in the later stage.

Over the decades many blood flow simulation studies have been carried out with the incompressible fluid flow assumption [63-78], which are useful only for simulating the creeping flow conditions in HCS. Herein, we established the proof of the concept of DDT and AHS at the creeping inflow condition in an internal diabatic flow system (see Figure 3) through in silico modeling at a critical total-to-static pressure ratio (CPR) where the compressibility effect is significant. The importance of this interdisciplinary study design is succinctly reviewed in the subsequent background section for highlighting the research question pertaining to an authentic prediction of LCDI and LCHI.

\section{Background}

Of late many in silico studies have been reported in base fluids and nanofluids for various industrial applications without an authentic validation of the results with benchmark data. As the pressure of the nanofluid rises, average-mean-free-path diminishes and thus, the Knudsen number lowers heading to a zero-slip wall-boundary condition with compressible viscous (CV) flow regime. ${ }^{[2]}$ V.R.S.Kumar et al. ${ }^{[1-3]}$ presented an exact analytical solution, which is capable to predict precisely the three-dimensional boundary-layer blockage factor (named herein as blockage factor) of diabatic fluid flow systems at the zero-slip-length. The innovation of the Sanal flow choking model was established through the entropy relation, as it meets all the conservation laws of nature. ${ }^{[1]}$ The physical insight of the Sanal flow choking and streamtube flow choking demonstrated herein sheds light on getting answers of several unanswered research questions in advanced science.

V.R.S.Kumar et al. ${ }^{[1-9]}$ established that there are likelihoods of Sanal flow choking in HCS (see Figure 1(ah) as the central illustration), after attaining the critical blood pressure ratio. ${ }^{[1,7]}$ The experiences gained 
from the theoretical and in vitro findings (see Figure 2) prompted us for the internal flow simulation of the straight duct ending with a divergent port for examining Sanal flow choking and streamtube flow choking (see Figure 3 and Figure 4(a-b)) through the reliable in silico simulation. It is a well-recognized fact that, the entire governing equations for viscous flows are extremely challenging to solve analytically using the existing mathematical tools. Using the developing system of non-linear equations, the in silico simulation with multi-phase and multi-species composite fluid flow with oscillating boundary wall is also a challenging task. It is because of the fact that an accurate, strong and competent solution with the super fine grid system is critical for the high reliability in silico modelling. ${ }^{[1-3]}$

Physics of Sanal flow-choking received significant attention in the global scientific community for solving various research problems of topical interest. ${ }^{[1,2,7,8]}$ Certainly, using the Sanal flow choking model to predict the 3D blockage factor, the chemical rocket motor designer could optimize the grain port geometry with the maximum possible propellant loading density with the allied igniter, without inviting DDT and without any costly empirical design technique or in silico simulation. ${ }^{[2]}$ Of late (2020) V.R.S.Kumar et al. ${ }^{[2]}$ highlighted the physical significance of the detonation kernel associated with the 3D blockage factor and the critical pressure ratio (CPR) causing the phenomenon of Sanal flow choking in a constant area duct ending with a divergent port. Through this study, ${ }^{[2]}$ the fundamental cause of DDT in the chemical rocket has come to the foreground. Over the centuries the scientific communities under the strong impression that at the creeping inflow condition DDT won't occur in a straight duct ending with a divergent region. We could authentically disprove this wrong notion on DDT through a closed-form analytical model, in silico results ${ }^{[3]}$ and the full motor static test results. ${ }^{[1]}$ Thereby, a popular research question revolving through the globe over the centuries has been settled with a cogent answer. In brevity, it says that due to the Sanal flow choking the creeping or low subsonic flow (continuum or noncontinuum) will get augmented to the supersonic flow condition in a straight duct ending with a divergent port and create possible shock waves and shock diamonds due to streamtube flow choking (see Figure 4 (a-b)). Note that the Sanal flow choking and the streamtube flow choking are new theoretical concepts applicable to both the continuum and non-continuum fluid flows. Once the streamlines compacted, the considerable pressure difference attains within the streamtube and the flow within the streamtube gets enhanced to the constricted section for satisfying the continuity condition set up the conservation law of nature, which leads to the Sanal flow choking and supersonic flow development at a CPR due to the convergent-divergent (CD) shape of the streamtube (see Figure 4(a-b)). For authenticating the proof of the concept the analytical and in silico methodologies are presented in the subsequent section.

\section{Methodology}

Analytical and in silico methodologies are invoked herein for establishing the proof of the concept of the occurrence of DDT and AHS at the creeping inflow condition in a constant area duct ending with a divergence/bifurcation region (see Figure 3). Figure 3 is highlighting the Sanal flow choking condition in 
such a classical model of a real-world fluid flow system and Figure 4(a) is depicting the Sanal flow choking and streamtube flow choking corresponding to Figure 3. Figure 4(b) shows the enlarged view of streamline pattern and the streamtube flow choking in yocto to yotta scale internal and external flow systems. It is highlighting the CD duct flow effect in a streamtube leading to detonation in the chemical energy and environmental systems at a CPR. Physical situations of flow choking depicted in Figure 3 and Figure $4(a-b)$ are meeting the conditions set by the conservation laws of nature. This is a remarkable finding for solving various unresolved problems in aerospace, biomedical, chemical, environmental, material, mechanical and nanotechnology, oil and natural gas industries. ${ }^{[1]}$

At the unchoked flow condition pressure in the constricted region of the streamtube will be lower than the wider region and this physical situation leads to choked flow condition at the CPR. Note that CPR is governed by HCR. When the streamtube is compressed, the reduction in internal energy is transformed into an accelerated fluid flow motion to satisfy the law of conservation of mass, which leads to the Sanal flow choking in CD shaped streamtube heading to the generation of supersonic flow causing shock waves, pressure-overshoot and detonation in the downstream region of the streamtube. These analytical findings are corroborated with the in silico results presented in the subsequent section.

The fluid-throat induced internal flow choking in real-world fluid flow systems at the creeping inflow condition is a new concept, which is defined as Sanal flow choking, ${ }^{[1]}$ a phenomenon occurs due to the boundary layer blockage. ${ }^{[1-9]}$ The exact solution of the 3D boundary layer blockage (BLB), corresponding to LCDI (i.e., considering the lowest value of HCR (Ylowest) of the evolved gases), at the Sanal flow choking for diabatic flows (continuum / non-continuum) with respect to Figure 3 is given in Equation $1 . M_{i}$ is the subsonic upstream inflow Mach number. Figure 5 is the solution curve of Equation 1. Note that irrespective of the magnitude of the BLB factor, the Sanal flow choking occurs anywhere in the circulatory circuit once the flow attains the critical pressure ratio (see Figure 5). The critical pressure ratio is dictated by the heat capacity ratio (HCR or $Y$ ) of the evolved gas with the lowest HCR (see Equation 2 and 3 ). Note that BLB will never be zero in any real-world fluid flow system. ${ }^{[1,82]}$ Equation 2 represents the LCDI, which is estimated based on the $Y_{\text {lowest }}$ for attaining the Sanal flow choking condition. Equation 2 reveals that in any flow system, the total-to-static pressure ratio $\left(\mathrm{P}_{\text {total }} / \mathrm{P}_{\text {static }}\right)$, should at all times be lesser than the LCDI for negating the undesirable detonation. In the case of biological flows Equation 2 is re-cast with respect to the blood pressure ratio (BPR) and the blood/biofluid heat capacity ratio (BHCR) for 


$$
\begin{aligned}
& \left.B L B\right|_{@ M_{x i}=1}=\left[1-M_{i}^{1 / 2}\left[\frac{2}{\gamma_{\text {lowest }}+1}\left(1+\frac{\gamma_{\text {lowest }}-1}{2} M_{i}^{2}\right)\right]^{\frac{\gamma_{\text {lones }}+1}{4\left(1-\gamma_{\text {boust }}\right)}}\right] d_{i}
\end{aligned}
$$

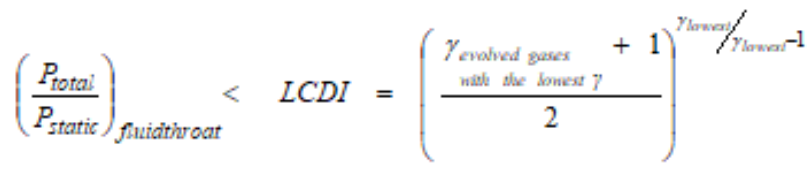

$$
\begin{aligned}
& \frac{S B P}{D B P}=B P R<L C H I=\left(\frac{B H C R+1}{2}\right)^{B H C R / B H C R-1} \\
& M_{i}=\frac{1}{\gamma_{\text {lowest }} 1 / 2}\left[\left(\gamma_{\text {lowest }}+1\right)\left(\frac{2}{\gamma_{\text {lowest }}+1}\right)^{\gamma_{\text {lowest }} / \gamma_{\text {lowest }}-1}-1\right]^{1 / 2} \\
& \bar{f}=\frac{d_{i}}{4 L^{*}}\left[\frac{1-M_{i}^{2}}{\gamma_{\text {lowest }} M_{i}^{2}}+\frac{\gamma_{\text {lowest }}+1}{2 \gamma_{\text {lowest }}} \ln \left[\frac{\left(\gamma_{\text {lowest }}+1\right) M_{i}^{2}}{2+\left(\gamma_{\text {lowest }}-1\right) M_{i}^{2}}\right]\right] \\
& \text { Mach number < } 1 \\
& \frac{\text { Mass flowrate }}{\text { Port crossectio nal area }}\left[\frac{C_{v} \text { (Diffilsivity) }}{P_{x \text { static }} \text { (Conductivity) }}\right]^{1 / 2}<1
\end{aligned}
$$

Biofluid Flow Velocity $\left[\frac{\text { Blood Density }}{(\text { Heat Capacity Ratio)(Diastolic Blood Pressure })}\right]^{1 / 2}<1$

$$
\left[\frac{(\text { BiofluidFlow Rate })_{\text {local }}(\text { Blood Viscosity hocal }}{(\text { BHCR })_{\text {lowest }}(D B P)(\text { Vessel Cross - sectional Area })_{\text {local }}}\right]^{1 / 2}<1
$$

$\frac{(\text { Reynolds Number)(Knematic Viscosity) }}{\text { Hydraulic Diameter }}\left[\frac{\text { Blood Density }}{(B H C R)(D B P)}\right]^{1 / 2}<1$

estimating the LCHI, which is presented herein as Equation 3. It is evident from Equation 3 that for negating AHS, the BPR should maintain always lesser than LCHI, which is governed by the lowest HCR of the evolved gas in the vessel. In the HCS the total pressure indicates the systolic blood pressure (SBP) and the static pressure shows the diastolic blood pressure (DBP).

Equation 4 shows the inlet Mach number estimation for getting diabatic flow choking in a straight duct. ${ }^{[1]}$ Equation 5 is a remarkable closed-form analytical model capable to predict the average friction 
coefficient, of any wall-bounded flow system, without any empiricism, for an authentic in silico simulation. ${ }^{[3]}$ If we know and the length-to-diameter $\left(/ / \mathrm{d}_{\mathrm{i}}\right)$ ratio we could fix the inflow Mach number for prohibiting DDT. Equation 5 will enable us for getting a choked flow condition at station 2 (see Figure 3) for the calibration of various in silico flow solvers by matching the numerically predicted blockage factor and the exact analytical solution.

The Sanal flow choking and streamtube flow choking are regulated by the physical situations set by Equations 1-6. It is a well known fact that for negating the flow choking Mach number should always be less than one in the system (see Equation 6). Equations 6(a-d) are the corollary of Equation 6 . The selfexplanatory Equations 6(a-d) derived from the compressible flow theory ${ }^{[1,4,83]}$ are representing Mach number, which are complimenting with Equation 2 and Equation 3. All these equations set the conditions for prohibiting Sanal flow choking and streamtube flow choking in any real-world fluid flow system. The individual or coupled effects of vessel geometry (stenosis) and the thermo-physical properties on flow choking can be easily discerned from Equations 6(a-d). These equations (Equations 6(a-d)) are well correlated with the clinical findings. ${ }^{[5-8]}$ It is evident from Equation $6(a, c, d)$ that an increase in blockage factor (i.e., a decrease in the port-cross-sectional-area), in any vessel due to plaque and/or boundary layer induced blockage, could increase the risk of Sanal flow choking in the creeping inflow condition. As directly evidenced from Equations 2, 3 and 6(b-d), the risk of Sanal flow choking could be negated by increasing the HCR of the evolved gas in the vessel. Note that the left hand side of Equations 6(a-d) are representing the magnitude of Mach number, which could be estimated from the biofluid properties and the vessel port area for estimating the risk of internal flow choking (see Figure 5). It is important to note that the flow Mach number must always be less than one in the circulatory circuit including the vasa vasorum for retaining the unchoked flow condition. In a nutshell, Equations $6(a-d)$ are the useful tools, highlighting the geometric and thermo-fluid dynamics parameters, for maintaining an unchoked flow condition in the circulatory circuit for negating the risk of AHS. It is important to note that an overdose of blood-thinning drug for reducing the blood-viscosity augments Reynolds number leading to highturbulence and enhanced boundary-layer-blockage (BLB), which increases the chances of cavitation and the Sanal-flow-choking leading to the shock wave and pressure-overshoot causing memory effect (stroke history) in viscoelastic vessels. Therefore, designing the precise blood-thinning regimen is vital for attaining the desired therapeutic efficacy and negating undesirable flow-choking leading to AHS. Briefly, the analytical models reveal that the relatively high and low blood viscosity are risk factors of AHS.

It is a well ascertained physical condition in the compressible flow theory that supersonic flow will be developed in the divergent region of a choked CD duct flow passage similar to an artery with divergent or bifurcation or vasospasm regions (see Figure 1 as the central illustration). At this physical situation ${ }^{[1,84]}$ there is a possibility of shock wave generation and pressure-overshoot, causation of asymptomatic aneurysm and/or AHS as the case may be. ${ }^{[1,37]}$

Largely, in the HCS the flow is laminar and it becomes turbulent due to blood thinners and/or due to local or seasonal effects. Note that the over dose of anticoagulant drugs decrease the dynamic viscosity 
of blood dramatically and as a result Reynolds number increases leading to enhanced BLB causing the Sanal flow choking. The flow turbulence increases the loss of energy in the form of friction, which augments the blockage factor in the vessels and generates heat and enhance the internal energy resulting a reduction in the blood/biofluid heat capacity ratio (BHCR). The flow turbulence augments the perfusion pressure vital to push the flow of blood, leading to internal flow choking and shock wave generation. It leads to establish that at a CPR in any straight duct ending with the sudden expansion / divergent / bifurcation region could lead to detonation at a low subsonic inflow condition.

It is crystal clear from the SANAL chart given in Figure 5 (the solution curve of Equation 1) that, irrespective of the percentage of blockage factor, the risk of detonation could be negated by retaining the total-to-static pressure rato in a fluid flow system always lower than LCDI. Similarly, irrespective of the percentage blockage of any artery, the risk of AHS could be reduced by maintaining the SBP/DBP ratio lower than LCHI, which is a unique function of HCR. For instance, if an internal flow system is having 50 \% port area blockage, there will NOT be any possibilities of the Sanal flow choking leading to detonation or hemorrhage provided the system maintains a flow Mach number lower than 0.3 or BPR < LCHI. The upper critical hemorrhage index ( $\mathrm{UCHI}$ ) could be estimated from the HCR of blood. At a CPR, the Sanal flow choking would occur in a vessel with gas embolism (i.e., when BPR $>$ LCHI) or without gas embolism (i.e., whwn BPR > UCHI) irrespective of the blockage factor (plaque and/or boundary layer blockage). In a nutshell, Figure 5 is explicitly showing the condition of DDT and ASH in an internal fluid flow system of any scale at the Sanal flow choking condition.

\section{In Silico Results}

For demonstrating the proof of the concept of the Sanal flow choking and streamtube flow choking in a classical fluid flow system in silico studies have been conducted using a validated flow solver. ${ }^{[3,4,85]}$ The results generated from the in silico modeling (see Figure 6(a-c) and Figure 7(a-f)) are conveying the message to the scientific community on the occurrence of the Sanal flow choking and streamtube flow choking in a diabatic fluid flow system leading to detonation and asymptomatic stroke. Please see movie S3 containing the in silico results.

It is appropriate to mention here that, the simulation of chemical reaction mechanisms containing shock waves and detonation reported in the open literature are not unique. ${ }^{[2]}$ Therefore, we deliberately set aside the reacting flow simulation in this fundamental pilot study for establishing one of the basic causes of DDT in the internal flow system. Figure 6(a-c) and Figure 7(a-f) show the in silico result highlighting the axial Mach number variations, sharp pressure spike and diminishing shock waves at the downstream region of the duct with bifurcation due to the Sanal flow choking and streamtube flow choking. Note that in the HCS, the large BPR oscillations could lead to the choking and unchoking phenomena creating high risk to the subjects (human being / animal) leading to an arrhythmia. Due to the periodic Sanal flow choking any valve, including heart valve, with $C D$ duct shaped flow passage will get more defects than convergent type valves as time advances in any flow circuit. This is corroborated with the clinical

findings. ${ }^{[1,7,8]}$ The fact is that during the Sanal flow choking the divergent region of the valve will 
experience the shock wave and pressure overshoot causing damage. Most heart valve problems involve the aortic and mitral valves, possibly because of its geometric shape similar to CD duct flow passage.

The valve defects can happen in water pipe line due to cavitation and shock waves. ${ }^{[1]}$ Further discussion on the defects of various types of valves is beyond the scope of this article.

Figures 7(a-f) are showing the enlarged view of the streamtube, demonstrating the shape of the streamtube and the Mach number contours at different time intervals before and after the Sanal flow choking. It is crystal clear from Figure 6 and Figure 7 that the streamlines are compressed and the pressure differences are significant within the streamtube and as a result the flow gets enhanced to the narrow region of the streamtube for satisfying the conservation law, which leads to Sanal flow choking and detonation due to the convergent-divergent (CD) shape of the streamtube. Normal shock and oblique shock waves are evidenced in the in silico results. The Sanal flow choking location, the strength of shock, and shock diamonds can be observed in Figure 6(a-c). Packed streamlines could be discerned in the constricted area of the streamtube (see Figure 6(a-b) and Figure 7(a-f)) where low pressure is evident. In the case of biological flows, the sonic-fluid throat location discerned in Figure 6(a-c) could alter due to the BPR oscillation, wall flexibility of the viscoelastic blood vessel, chemistry of multi-species and multiphase fluid flow, and pathophysiological conditions.

The objective of this study was to establish the phenomenon of the Sanal flow choking and streamtube flow choking through the analytical and in silico modeling of diabatic fluid flows, which we could achieve herein. In the case of HCS, the blood and/or biofluid could get evaporated at the higher temperature creating an undesirable formation of gases within the duct creating a detrimental flow choking due to low HCR of the evolved gas leading to gas embolism. ${ }^{[1-9]}$ Figure $6(a-c)$ and Figure 7(a-f) are analogous to biofluid choking effect in the circulatory circuit due to gas embolism. Briefly analytical and in silico results established that predicting the conditions of LCDI and LCHI, based on the lowest HCR of evolved gas, are inevitable for negating the undesirable DDT and ASH in any fluid flow system with credibility.

\section{Discussion}

Despite 40 years of study (Hoyle \& Fowler 1960), the mechanism whereby a degenerate carbon-oxygen white dwarf explodes, producing a Type la supernova (SN la), remains poorly understood. Early calculations assumed that central carbon ignition would lead to a detonation (Arnett 1969) that would incinerate the star entirely to iron. This proved inconsistent both with observations of features in the supernova spectrum from intermediate-mass elements and with detailed calculations of isotopic nucleosynthesis. Nowadays it is understood that prompt detonation does not occur because the core at ignition time is insufficiently isothermal.

Although it is controversial whether the deflagration will later make a transition to a detonation (Niemeyer \& Woosley 1997; Khokhlov et al. 1997; Niemeyer 1999), it is universally assumed that the runaway begins as a deflagration (Nomoto et al. 1976). 
Indeed, there may be great difficulty getting a viable supernova explosion if all the ignition occurs on one side (Niemeyer et al. 1996). Unless a transition to detonation occurs, or pulsational oscillations, it will be difficult to ever burn the other side. The explosion will then be subenergetic and produce too little $56 \mathrm{Ni}$.

(Ref> The Astrophysical Journal, 607:921-930, 2004 June 1)

Nature-2020.

We do not know whether the burning wave propagates through the white dwarf as a supersonic detonation or as a subsonic deflagration. We do not understand the details of initial ignition and runaway. We do not know the nature of the binary companion that feeds the white dwarf-whether it is a main sequence star, a subgiant star, a giant star, or another white dwarf. All these types of companions might occur with some frequency.

The result of all this ignorance is that theorists cannot predict-from first principles and with sufficient precision-the $56 \mathrm{Ni}$ yields, explosion energies, light curves, and spectra of type la supernovae to justify them as cosmological theodolites

\section{Concluding Remarks}

The theoretical discovery of Sanal flow choking received considerable attention in the central science for resolving centuries long unresolved problems. Understanding flow physics and the transport of fluid from creeping inflow to the supersonic flow at the yocto to yotta scale systems are of significant interest for testing classical theories of the continuum and non-continuum fluid flows for solving varieties of industrial problems with credibility. Gotthard Seifert ${ }^{[102]}$ reported ab initio in silico simulations, which provide a sign of the development of the molecular and electronic structure of an explosive undergoing detonation. Moseler and Landman ${ }^{[103]}$ used molecular dynamics (MD) simulations of nanoscale jets to encounter a rupture profile not illustrated by macroscopic theory. Of late (2020), Chengxi Zhao ${ }^{[104]}$ reported that the soundness of the traditional theories at the microscale and nanoscale has been taken into question. Authors reported that the thermal fluctuations are spontaneously occurring within molecular dynamics (MD) simulations. D.M.Holland et al. ${ }^{[105]}$ further reported that the time dependent mass flow rate predicted using their enhanced in silico simulation matches well with full molecular dynamics (MD) simulation and highlighted that the traditional in silico results of such cases are incompetent. It leads to say that in real world scientific experiments of complex nano-microscale systems the robustness of in silico model needs to be tested to featuring the actual fluid characteristics in a nontrivial geometry at the nanoscale. Singh and Myong ${ }^{[106]}$ reported that for improved modeling efforts, the joint effect of material properties, the scale and shape of the flowing medium on fluid flow must be taken into account, which we conclusively addressed herein through the closed-form analytical models capable to solve real-world fluid flow (continuum / non-continuum) problems experiencing deflagration to detonation transition of any scale. 
The physics of detonation chemistry presented herein through the Sanal flow choking/ streamtube flow choking phenomenon is a pointer for prediting detonation in yocto to yotta scale systems and beyond, which includes supernova explosion. ${ }^{[107]}$ Note that the mechanism whereby a degenerate carbon-oxygen white dwarf explodes, producing a Type la supernova ( $\mathrm{SN} \mathrm{la),} \mathrm{still} \mathrm{remains} \mathrm{poorly}$ understood. ${ }^{[108]}$ Earlier researchers do not know whether the burning wave propagates through the white dwarf as a supersonic detonation or as a subsonic deflagration. ${ }^{[107-121] . ~ H e r e i n, ~ w e ~ p r o v i d e ~ t h e ~ p r o o f ~ o f ~}$ the concept of the Sanal flow choking and streamtube flow choking causing the sharp pressure spike due to shock wave formation. The streamtube flow choking is a radical theory in predicting the deflagration to detonation transition in both internal and external flows. At the low subsonic inlet conditions, the realworld fluid flow (continuum / non-continuum) system with the divergent/bifurcation duct could incline to deflagration-to-detonation-transition (DDT) due to the phenomenon of the boundary-layer-blockage (BLB) factor induced the Sanal flow choking in a wall-bounded or streamline bounded flows at a critical pressure ratio. The Sanal flow choking is vulnerable to catastrophic failures of reacting and non-reacting fluid flow systems with sudden expansion/divergent port due to the cavitation, shock wave and detonation as the case may be. At the lower critical detonation or hemorrhage index, the critical pressure ratio of the chemical energy system and the blood pressure ratio (BPR) of the subjects (human being / animal) are unique functions of the heat capacity ratio (HCR) of the gas in the duct. Numerical simulations are carried out with creeping inflow conditions using a calibrated viscous flow solver ${ }^{[3]}$ for demonstrating the novel concept of the fluid-throat induced Sanal flow choking followed by the shock wave generation and pressure overshoot in a straight-tube ending with a divergent port, similar to an artery with the divergent / bifurcation region. We concluded that the detonation kernel is more sensitive in the reacting flows generating the leading species with low HCR. We also concluded from the analytical solution that the biofluid / blood with low HCR is more susceptible to asymptomatic hemorrhagic stroke (AHS) in the circulatory circuit of all subjects due to an early flow choking. The risk of Sanal flow choking and streamtube flow choking could be negated by breaking the blockage and/or increasing the HCR of the evolved gases in the tube for keeping the total-to-static pressure ratio always lower than the lower critical detonation / hemorrhage index in any fluid flow system. In silico results reported herein shed light for the biological, chemical, energy, environmental, material and aerospace systems design and drug discovery. The result of this study is a strong exposition to the industry for the elimination of the detonation in any energy system with confidence, which was an unknown fact to the scientific communities for several decades. ${ }^{[1-4,86-91]}$

Using the exact solution reported herein a detonation free energy system could be devised authoritatively by regulating the inflow condition, selecting the fluid viscosity, HCR and the average wallfriction coefficient based on the upstream length-to-diameter ratio of the flow system for achieving the condition LCDI $>\left(\mathrm{P}_{\text {total }} / \mathrm{P}_{\text {static }}\right)_{\text {fluid-throat. }}$. In other words, we can reduce the risk of DDT by increasing the HCR. In the case of biological systems by keeping BPR < LCHI, we could reduce the risk of AHS. ${ }^{[1-9]}$ It can be achieved by increasing the BHCR, which could simultaneously reduce blood viscosity and turbulence. A fluid-structural simulation could be useful to offer cogent answers to clinical questions pertaining to AHS and aneurysm, which are beyond the scope of this manuscript. In a nutshell, this basic research 
article sheds light for discovering the likelihoods of biofluid flow choking, Sanal flow choking and Streamtube flow choking in real-world fluid flow system. Briefly, analytical, and in silico results highlighted in this article will complement preclinical in vivo assessments in mega and nanotubes and can fine-tune decision making steps in biomaterial design and drug discovery through the nanotechnology. ${ }^{\text {[9-101] }}$ This article is a part of the scientific odyssey that resulted from a collaboration among members from various research groups, viz., rocket propulsion, physical and material science, chemical science, environmental science, biomaterials, biomedical, cardiology, nanotechnology and nanomedicine.

\section{Supplementary Materials}

Movie S1: In vitro result demonstrating the shock wave generation in a viscoelastic tube with vasospasm at a critical pressure ratio: https://youtu.be/59E6pI3L5Rc

Movie S2: In vitro result demonstrating the internal flow choking and the shock wave generation in a viscoelastic tube with vasospasm at different locations at a different pressure ratio: https://youtu.be/UQqtpQaUVHg

Movie S3: In silico result demonstrating the boundary layer blockage induced the Sanal flow choking at a critical pressure ratio: https://youtu.be/eFndUAU_m5I

\section{Declarations}

\section{Acknowledgments}

The first author thanks SERB/DST, Government of India for the necessary support for originating this historical work.

\section{Data availability}

The raw data required to reproduce the in silico results are available with the corresponding author and could be shared on request.

\section{References}

[1] V.R.Sanal Kumar, Vigneshwaran Sankar, Nichith Chandrasekaran, Ajith Sukumaran, Sulthan Ariff Rahman Mohamed Rafic, Roshan Vignesh Baskaran, R.S.Bharath, Charlie Oommen, Pradeep Kumar Radhakrishnan, Shiv Kumar Choudhary, "Sanal Flow Choking: A Paradigm Shift in Computational Fluid Dynamics Code Verification and Diagnosing Detonation and Hemorrhage in Real-World Fluid-Flow Systems," Global Challeges, Wiley Publication, May 2020, PMCID: PMC7267099, PMID: 32837737, https://doi.org/10.1002/gch2.202000012

[2] V.R.Sanal Kumar, Nichith Chandrasekaran, Vigneshwaran Sankar, Ajith Sukumaran, et al., "Deflagration to Detonation Transition in Chemical Rockets with Sudden Expansion / Divergence 
Regions." AIAA Propulsion and Energy 2020 Forum, August 24-28, 2020, AIAA 2020-3520, https://doi.org/10.2514/6.2020-3520

[3] V.R. Sanal Kumar, Vigneshwaran Sankar, Nichith Chandrasekaran, Vignesh Saravanan, Vishnu Natarajan, Sathyan Padmanabhan, Ajith Sukumaran, Sivabalan Mani, Tharikaa Rameshkumar, Hema Sai Nagaraju Doddi, Krithika Vysaprasad, Sharad Sharan, Pavithra Murugesh, S.Ganesh Shankar, Mohammed Niyasdeen Nejaamtheen, Roshan Vignesh Baskaran, Sulthan Ariff Rahman Mohamed Rafic, Ukeshkumar Harisrinivasan, Vivek Srinivasan, Rajshree C J, Arun Krishnan, Abhishesh Pal, Gayathri V Panicker, and Abhirami Rajesh, "Boundary layer Blockage, Venturi Effect and Cavitation Causing Aerodynamic Choking and Shock Waves in Human Artery Leading to Hemorrhage and Massive Heart Attack - A New Perspective," AIAA Paper No. AIAA-2018-3962. (2018). https://doi.org/10.2514/6.20183962

[4] V.R. SanalKumar, Vigneshwaran Sankar, Nichith Chandrasekaran, Vignesh Saravanan, Vishnu Natarajan, Sathyan Padmanabhan, Ajith Sukumaran, Sivabalan Mani, Tharikaa Rameshkumar, Hema Sai Nagaraju Doddi, Krithika Vysaprasad, Sharad Sharan, Pavithra Murugesh, S.Ganesh Shankar, Mohammed Niyasdeen Nejaamtheen, Roshan Vignesh Baskaran, Sulthan Ariff Rahman Mohamed Rafic, Ukeshkumar Harisrinivasan, and Vivek Srinivasan, "A Closed-form Analytical Model for Predicting 3D Boundary Layer Displacement Thickness for the Validation of Viscous Flow Solvers," American Institute of Physics (AIP) Advances, 2018, 8, 025315, https://doi.org/10.1063/1.5020333.

[5] V.R.Sanal Kumar, Bharath R.S, Pradeep Kumar Radhakrishnan, Nichith Chandrasekaran, Charlie Oommen, Raghunandan B.N, Shiv Kumar Choudhary (2019) In vitro prediction of the lower-critical hemorrhage index. The Asian Society for Cardiovascular and Thoracic Surgeory, IACTSCON2019, Chennai, India, 21-24 Feb 2019. Abstract ID: 694.

[6] V.R.Sanal Kumar, Bharath RS, Nichith Chandrasekaran, Charlie Oommen, Raghunandan BN, Shiv Kumar Choudhary, Pradeep Kumar Radhakrishnan, "High Heat Capacity of Blood Reduces Risk on Myocardial Infarction," World Congress on Cardiac Sciences-2018, IISc, Bengaluru, India, BioGenesis, The Journal of Biology and Medicine, Vol.1, November 2018.

[7] V.R.Sanal Kumar et al., Very Low and High Blood Viscosity Are Risk Factors for Internal-FlowChoking Causing Asymptomatic Cardiovascular Disease, Journal of American College of Cardiology, JACC082220-4360, August 2020 (Under review).

[8] V.R.Sanal Kumar et al., Lopsided Blood-thinning Drug Increases the Risk of Internal Flow Choking Leading to Shock Wave Generation Causing Asymptomatic Cardiovascular Disease, Global Challeges, gch2.202000076, August 2020 (Under review).

[9] V.R.Sanal Kumar, Vigneshwaran Sankar, Nichith Chandrasekaran, and Sulthan Ariff Rahman Mohamed Rafic, "Discovery of SANAL flow choking phenomenon," Patent Application No. 201841049355, Chennai, India, Date of online publication: January 4, 2019. 
[10] J.Buckmaster, P.Clavin, A.Liñán, M.Matalon, N.Peters, G.Sivashinsky, F.A.Williams, Combustion theory and modeling, Proceedings of the Combustion Institute, Volume 30, Issue 1, January 2005, Pages 1-19.

[11] Charles K.Westbrook, YasuhiroMizobuchi, Thierry J.Poinsot, Phillip J.Smith, JürgenWarnatz, Computational combustion, Proceedings of the Combustion Institute, Volume 30, Issue 1, January 2005, Pages 125-157

[12] Viswanath R.Katta, Kevin Y.Cho, John L.Hoke, Joshua R.Codoni, Frederick R.Schauer, William M.Roquemore, Effect of increasing channel width on the structure of rotating detonation wave, Proceedings of the Combustion Institute, Volume 37, Issue 3, 2019, Pages 3575-3583.

[13] AkiraKawasaki, Tomoyalnakawa, JiroKasahara, KeisukeGoto, KenMatsuoka, AkikoMatsuo, IkkohFunaki, Critical condition of inner cylinder radius for sustaining rotating detonation waves in rotating detonation engine thruster, Proceedings of the Combustion Institute, Volume 37, Issue 3, 2019, Pages 3461-3469.

[14] Scott I.Jackson, Carlos Chiquete, Mark Short, An intrinsic velocity-curvature-acceleration relationship for weakly unstable gaseous detonations, Proceedings of the Combustion Institute, Volume 37, Issue 3, 2019, Pages 3601-3607.

[15] J.Chao, T.Otsuka, J.H.S.Lee, An experimental investigation of the onset of detonation, Proceedings of the Combustion Institute, Volume 30, Issue 2, January 2005, Pages 1889-1897.

[16] Jian-Ling Li, Wei Fan, Chuan-Jun Yan, Hong-Yan Tu, Kai-Cheng Xie Performance enhancement of a pulse detonation rocket engine, Proceedings of the Combustion Institute, Volume 33, Issue 2, 2011, Pages 2243-2254.

[17] Elaine S.Oran, Understanding explosions - From catastrophic accidents to creation of the universe, Proceedings of the Combustion Institute, Volume 35, Issue 1, 2015, Pages 1-35.

[18] ShinichiMaeda, Masashi Fujisawa, Shogolenaga, Keisuke Hirahara, Tetsuro Obara, Effect of sandpaper-like small wall roughness on deflagration-to-detonation transition in a hydrogen-oxygen mixture, Proceedings of the Combustion Institute, Volume 37, Issue 3, 2019, Pages 3609-3616.

[19] Craig T. Johansen, Gaby Ciccarelli, Visualization of the unburned gas flow field ahead of an accelerating flame in an obstructed square channel, Combustion and Flame, Volume 156, Issue 2, February 2009, Pages 405-416.

[20] Scott I.Jackson, Larry G.Hill, Runaway reaction due to gas-dynamic choking in solid explosive containing a single crack, Proceedings of the Combustion Institute, Volume 32, Issue 2, 2009, Pages 2307-2313 
[21] J Czerwinska (2009) Continuum and Non-continuum Models for Micro- and Nanoflows, VKI-RTO lectures monography, 2009, https://pdfs.semanticscholar.org/cc1f/94aa7294753c3304dd3e2cafbf2c9c801fa9.pdf

[22] Xiaohui Lin, Fu-bing Bao, Xiaoyan Gao, and Jiemin Chen, Molecular Dynamics Simulation of Nanoscale Channel Flows with Rough Wall Using the Virtual-Wall Model, Journal of Nanotechnology , Volume 2018, https://doi.org/10.1155/2018/4631253

[23] M. W. Collins and C. S. König, Micro and Nano Flow Systems for Bioanalysis, Springer, New York, NY, USA, 2012.

[24] M. Z. Yu, X. T. Zhang, G. D. Jin, J. Z. Lin, and M. Seipenbusch, "A new moment method for solving the coagulation equation for particles in Brownian motion," Aerosol Science and Technology, vol. 42, no. 9, pp. 705-713, 2008.View at: Publisher Site | Google Scholar

[25] M. Gad-el-Hak, MEMS: Introduction and Fundamentals, CRC Press, Boca Raton, FL, USA, 2010.

[26] Whitby, M., Quirke, N. Fluid flow in carbon nanotubes and nanopipes. Nature Nanotech 2, 87-94 (2007). https://doi.org/10.1038/nnano.2006.175

[27] Longhurst, M. \& Quirke, N. Environmental effects on the radial breathing modes of carbon nanotubes in water. J. Chem. Phys. 124, 234708 (2006).

[28] Sokhan, V. P., Nicholson, D. \& Quirke N. Fluid flow in nanopores: accurate boundary conditions for carbon nanotubes. J. Chem. Phys. 117, 8531-8539 (2002).

[29] Supple, S. \& Quirke, N. Molecular dynamics of transient oil fl ows in nanopores I: Imbibition speeds for single wall carbon nanotubes. J. Chem. Phys. 121, 8571-8579 (2004).

[30] Qi-Long Yan, Michael Gozin, Feng-Qi Zhao, Adva Cohen and Si-Ping Pang, Highly energetic compositions based on functionalized carbon nanomaterials, Nanoscale, Issue 9, 2016

[31] Krishnan, D., Kim, F., Luo, J., Cruz-Silva, R., Cote, L. J., Jang, H. D., \& Huang, J. (2012). Energetic graphene oxide: Challenges and opportunities. Nano Today, 7(2), 137-

152. https://doi.org/10.1016/j.nantod.2012.02.003

[32] Mattia, D., et al. Effect of graphitization on the wettability and electrical conductivity of CVDcarbon nanotubes and fi Ims. J. Phys. Chem. B 110, 9850-9855 (2006).

[33] Skoulidas, A. I., Ackerman, D. M., Johnson, J. K. \& Sholl, D. S. Rapid transport of gases in carbon nanotubes. Phys. Rev. Lett. 89, 185901 (2002)., https://doi.org/10.1103/PhysRevLett.89.185901

[34] Ermolaev, B.S., Belyaev, A.A., Viktorov, S.B. et al. Nonideal regimes of deflagration and detonation of black powder. Russ. J. Phys. Chem. B 4, 428-439 (2010). 
https://doi.org/10.1134/S1990793110030103.

[35] G. V. Sakovich, A. S. Zharkov and E. A. Petrov, Results of research into the physicochemical processes of detonation synthesis and nanodiamond applications, Nanotechnol. Russ., 2013, 8 , $581-$ 591

[36] MinfengHuo, LiyingWang, YuChen, JianlinShi, Nanomaterials/microorganism-integrated microbiotic nanomedicine, Nano Today, Volume 32, June 2020, 100854, https://doi.org/10.1016/j.nantod.2020.100854

[37] J.J.Wang, R.T.Zheng, J.W.Gao, G.Chen, Heat conduction mechanisms in nanofluids and suspensions, Nano Today, Volume 7, Issue 2, April 2012, Pages 124-136, https://doi.org/10.1016/j.nantod.2012.02.007

[38] SabineHauert, Spring Berman, Radhika Nagpal, Sangeeta N.Bhatia, A computational framework for identifying design guidelines to increase the penetration of targeted nanoparticles into tumors, Nano Today, Volume 8, Issue 6, December 2013, Pages 566-576, https://doi.org/10.1016/j.nantod.2013.11.001

[39] Cordelia Sealy, A new twist on growing carbon nanotubes, Nano Today, Volume 30, February 2020, 100840, https://doi.org/10.1016/j.nantod.2020.100840

[40] The risks of nanomaterial risk assessment. Nat. Nanotechnol. 15, 163 (2020). https://doi.org/10.1038/s41565-020-0658-9

[41] Matsumoto, Y., Nichols, J. W., Toh, K., Nomoto, T., Cabral, H., Miura, Y., Kataoka, K. (2016). Vascular bursts enhance permeability of tumour blood vessels and improve nanoparticle delivery. Nature Nanotechnology, 11(6), 533-538. doi:10.1038/nnano.2015.342

[42] White, S., Geubelle, P. Get ready for repair-and-go. Nature Nanotech 5, 247-248 (2010). https://doi.org/10.1038/nnano.2010.66

[43] Cingolani, R. The road ahead. Nature Nanotech 8, 792-793 (2013). https://doi.org/10.1038/nnano.2013.238

[44] Faria, M., Björnmalm, M., Thurecht, K.J. et al. Minimum information reporting in bio-nano experimental literature. Nature Nanotech 13, 777-785 (2018). https://doi.org/10.1038/s41565-018-02464

[45] Moscatelli, A. Nanoparticles go with the flow. Nature Nanotech (2013). https://doi.org/10.1038/nnano.2013.37

[46] V.R.Sanal Kumar, "Biofluid Choking a Paradigm Shift in the Diagnostic Sciences of Stroke - Blood Pressure Ratio and Heat Capacity Ratio Are the Risk Factors for Hemorrhage and Heart Attack," OSF Preprints, February 5, 2020, doi:10.31219/osf.io/bce2n. 
[47] V.R.Sanal Kumar, Shiv Kumar Choudhary, Pradeep Kumar Radhakrishnan, Suresh Menon, Vrishank Raghav, K. K. Narayanan Namboodiri, Sapna Erat Sreedharan, Bharath R.S, Nichith Chandrasekaran, Charlie Oommen, Vigneshwaran Sankar, Ajith Sukumaran, Arun Krishnan, Abhishesh Pal, Tharikaa Ramesh kumar, Abhirami Rajesh, "Critical Blood Pressure Ratio and Memory Effects Are Risk Factors for Stroke - Discovery of Biofluid Choking a Paradigm Shift in the Diagnostics Sciences of Hemorrhage and Ischaemic Heart Disease." OSF Preprints, February 5, 2020, doi:10.31219/osf.io/t67jv.

[48] V.R.Sanal Kumar, Raghunandan, B.N., Kawakami,T., Kim, H.D., Setoguchi,T., and Raghunathan,S.,"Studies on Boundary Layer Blockage and Internal Flow Choking in Dual-thrust Motors," Journal of Propulsion and Power, Vol.24, No.2, 2008, pp. 224-234, doi: 10.2514/1.30649

[49] V.R.Sanal Kumar, H.D.Kim, B.N.Raghunandan, A.Sameen,T.Setoguchi, and S.Raghunathan, FluidThroat Induced Shock Waves During the Ignition Transient of Solid Rockets, AlAA Journal of Spacecraft and Rockets, Vol. 43, No. 1, (2006) 225-228.

[50] V.R.Sanal Kumar, B.N.Raghunandan, H.D.Kim, A.Sameen,T.Setoguchi, and S.Raghunathan, Starting Transient Flow Phenomena in Inert Simulators of SRMs with Divergent Ports," AIAA Journal of Propulsion and Power, Vol. 22, No. 5, (2006) 1138-1141.

[51] V.R.Sanal Kumar, B.N.Raghunandan, H.D.Kim, A.Sameen, T.Setoguchi, and S.Raghunathan, Studies on Internal Flow Choking in Dual-Thrust Motors," AIAA Journal of Spacecraft and Rockets, Vol. 43, No. 5. (2006) 1139-1143.

[52] V R Sanal Kumar, Vigneshwaran Sankar, Nichith Chandrasekaran, Sulthan Ariff Rahman $M$ and Roshan Vignesh Baskaran, Modeling of Sanal Flow Choking Condition and Design Optimization of High Performance Dual-thrust SRMs, AIAA 2018-4693. https://doi.org/10.2514/6.2018-4693

[53] VR Sanal Kumar, Vigneshwaran Sankar, Nichith Chandrasekaran, Pavithra Murugesh, Sulthan Ariff Rahman M and Roshan Vignesh Baskaran, Prediction of 3D Boundary Layer Blockage and the Grain Design Optimization of HVT Dual-thrust Hybrid Rockets, AIAA 2018-4446, https://doi.org/10.2514/6.2018-4446.

[54] Nichith Chandrasekaran, Vigneshwaran Sankar, Sathyan Padmanabhan, V.R.Sanal Kumar, Ajith Sukumaran, Sivabalan Mani and Pavithra Murugesh, Studies on Oscillating Boundarylayer During the Ignition Transient of Dual-thrust Solid Rocket Motors, AIAA 2017-4691, 53rd AIAA/SAE/ASEE Joint Propulsion Conference, https://doi.org/10.2514/6.2017-4691

[55] Nichith Chandrasekaran, Vigneshwaran Sankar, Mohammed Niyasdeen Nejaamtheen, Kumaresh Selvakumar, Sulthan A. Rahman and V R Sanal Kumar, Analytical and Numerical Predictions of Boundary Layer Blockage in Dual Thrust Motors, 2018 Joint Propulsion Conference, , July 9-11, 2018, Cincinnati, Ohio, U.S.A., AIAA 2018-4880, https://doi.org/10.2514/6.2018-4880 
[56] Vigneshwaran Sankar, Vishnu Natarajan, Nichith Chandrasekaran, Sulthan Ariff Rahman M, Roshan Vignesh Baskaran, and V.R.Sanal Kumar, 3D Boundary Layer Blockage and the Average Friction Coefficient at the Sanal Flow Choking Condition for the CFD Code Validation, Calibration and Verification, AIAA 2018-4883, https://doi.org/10.2514/6.2018-4883

[57] Ajith S et al. and V.R.Sanal Kumar, Studies on Flame Spread Acceleration and Detonation Kernel in a Dual-thrust Rocket, AIAA Propulsion and Energy 2019 Forum, AIAA 2019-4209, https://doi.org/10.2514/6.2019-4209.

[58] Victor S Abrukov, Alexander N. Lukin, Charlie Oommen,Nichith Chandrasekaran, Rajaghatta S. Bharath, V.R Sanal Kumar, Mikhail V Kiselev, and Darya A Anufrieva, Development of the Multifactorial Computational Models of the Solid Propellants Combustion by Means of Data Science Methods - Phase II, AIAA 2018-4961, AIAA Propulsion and Energy Forum. https://doi.org/10.2514/6.2018-4961

[59] M. Brust, C. Schaefer, R. Doerr, L. Pan, M. Garcia, P. E. Arratia, C. Wagner, Phys. Rev. Lett. 2013, 110, 078305

[60] S. Varchanisa, Y. Dimakopoulosa, Christian Wagnerb, J. Tsamopoulosa, Soft Matter,2018, DOI: 10.1039/C8SM00061A

[61] Frank J. Millero, Richard W. Curry, and Walter Drost-Hansen, Isothermal Compressibility of Water at Various Temperatures, Journal of Chemical and Engineering Data, Vol. 14, No. 4, October 1969, pp. 422425, https://doi.org/10.1021/je60043a018

[62] Rana A. Fine and Frank J. Millero, Compressibility of Water as a Function of Temperature and Pressure, AIP The Journal of Chemical Physics, 59(10):5529-5536, November 1973, DOI: 10.1063/1.1679903.

[63] T.Hayat, Sohail A.Khan, M.ljaz Khan, A.Alsaedi, Theoretical investigation of Ree-Eyring nanofluid flow with entropy optimization and Arrhenius activation energy between two rotating disks, Computer Methods and Programs in Biomedicine, Volume 177, August 2019, Pages 57-68, https://doi.org/10.1016/j.cmpb.2019.05.012

[64] T.Hayat, Sohail A. Khan, M.ljaz Khan, A.Alsaedi, Theoretical investigation of Ree-Eyring nanofluid flow with entropy optimization and Arrhenius activation energy between two rotating disks, Computer Methods and Programs in Biomedicine, Volume 177, August 2019, Pages 57-68, https://doi.org/10.1016/j.cmpb.2019.05.012

[65] T.Hayat, M. Ijaz Khan, M.Waqas, A.Alsaedi, M.Farooq, Numerical simulation for melting heat transfer and radiation effects in stagnation point flow of carbon-water nanofluid, Computer Methods in Applied Mechanics and Engineering, Volume 315, 1 March 2017, Pages 1011-1024, https://doi.org/10.1016/j.cma.2016.11.033 
[66] T.Hayat. M. ljazKhan, M.Farooq, Tabassam Yasmeen, A.Alsaedi, Stagnation point flow with Cattaneo-Christov heat flux and homogeneous-heterogeneous reactions, Journal of Molecular Liquids, Volume 220, August 2016, Pages 49-55, https://doi.org/10.1016/j.molliq.2016.04.032

[67] Tasawar Hayat, Muhammad ljaz Khan, Sumaira Qayyum, Ahmed Alsaedi, Entropy generation in flow with silver and copper nanoparticles, Colloids and Surfaces A: Physicochemical and Engineering Aspects, Volume 539, 20 February 2018, Pages 335-346, https://doi.org/10.1016/j.colsurfa.2017.12.021

[68] Tasawar Hayat, Muhammad ljaz Khan, Ahmed Alsaedi, Muhammad Imran Khan, Joule heating and viscous dissipation in flow of nanomaterial by a rotating disk, International Communications in Heat and Mass Transfer, Volume 89, December 2017, Pages 190-197, https://doi.org/10.1016/j.icheatmasstransfer.2017.10.017

[69] Tasawar Hayat, Muhammad ljaz Khan, Tufail Ahmad Khan, Muhammad Imran Khan, Salman Ahmad, Ahmed Alsaedi, Entropy generation in Darcy-Forchheimer bidirectional flow of water-based carbon nanotubes with convective boundary conditions, Journal of Molecular Liquids, Volume 265, 1 September 2018, Pages 629-638, https://doi.org/10.1016/j.molliq.2018.06.017

[70] Tasawar Hayat, Sumaira Qayyum, Muhammad ljaz Khan, Ahmed Alsaedi, Current progresses about probable error and statistical declaration for radiative two phase flow using $\mathrm{Ag} \mathrm{H}_{2} \mathrm{O}$ and $\mathrm{Cu} \mathrm{H}_{2} \mathrm{O}$ nanomaterials, International Journal of Hydrogen Energy, Volume 42, Issue 49, 7 December 2017, Pages 29107-29120, https://doi.org/10.1016/j.ijhydene.2017.09.124

[71] Muhammad ljaz Khan, Muhammad Waqas, Tasawar Hayat, Ahmed Alsaedi, A comparative study of Casson fluid with homogeneous-heterogeneous reactions, Journal of Colloid and Interface Science, Volume 498, 15 July 2017, Pages 85-90, https://doi.org/10.1016/j.jcis.2017.03.024

[72] M. Ijaz Khan, Sumaira Qayyum, T.Hayat, M. ImranKhan, A.Alsaedi, Tufail Ahmad Khan, Entropy generation in radiative motion of tangent hyperbolic nanofluid in presence of activation energy and nonlinear mixed convection, Physics Letters A, Volume 382, Issue 31, 10 August 2018, Pages 2017-2026, https://doi.org/10.1016/j.physleta.2018.05.021

[73] M.ljaz Khan, AmitKumar, T.Hayat, M.Waqas, Ramayan Singh, Entropy generation in flow of Carreau nanofluid, Journal of Molecular Liquids, Volume 278, 15 March 2019, Pages 677-687, https://doi.org/10.1016/j.molliq.2018.12.109

[74] Madiha Rashid, M. ljazKhan, Tasawar Hayat, M. Imran Khan, Ahmed Alsaedi, Entropy generation in flow of ferromagnetic liquid with nonlinear radiation and slip condition, Journal of Molecular Liquids, Volume 276, 15 February 2019, Pages 441-452, https://doi.org/10.1016/j.molliq.2018.11.148

[75] Waleed Ahmed Khan, M, ljaz Khan, M., Hayat, T., Alsaedi, A., Entropy generation minimization (EGM) of nanofluid flow by a thin moving needle with nonlinear thermal radiation, Physica B: Physics of Condensed Matter, Volume 534, p. 113-119, 10.1016/j.physb.2018.01.023 
[76] Sumaira Qayyum, M.Ijaz Khan, T.Hayat, A.Alsaedi, M.Tamoor, Entropy generation in dissipative flow of Williamson fluid between two rotating disks, International Journal of Heat and Mass Transfer, Volume 127, Part C, December 2018, Pages 933-942, https://doi.org/10.1016/j.ijheatmasstransfer.2018.08.034

[77] Sumaira Qayyum, T.Hayat, Muhammad ljaz Khan, Muhammad Imran Khan, A.Alsaedi, Optimization of entropy generation and dissipative nonlinear radiative Von Karman's swirling flow with Soret and Dufour effects, Journal of Molecular Liquids, Volume 262, 15 July 2018, Pages 261-274, https://doi.org/10.1016/j.molliq.2018.04.010

[78] A.K. Pandey, M. Kumar, Boundary layer flow and heat transfer analysis on Cu-water nanofluid flow over a stretching cylinder with slip, Alexandria Eng. J. (2017), http://dx.doi.org/10.1016/j.aej.2017.01.017

[79] Michael A. Willcox, M. Quinn Brewster, K. C. Tang, D. Scott Stewart, and Igor Kuznetsov, "Solid Rocket Motor Internal Ballistics Simulation Using Three-Dimensional Grain Burnback," Journal of Propulsion and Power, Vol. 23, No. 3, May-June 2007. doi: 10.2514/1.22971

[80] Blomshield, F. S., and Mathes, H. B., "Pressure Oscillations in Post- Challenger Space Shuttle Redesigned Solid Rocket Motors," Journal of Propulsion and Power, Vol. 9, No. 2, March-April 1993, pp. 217-221. doi: 10.2514/3.23612

[81] Balachandar, S., Buckmaster, J. D., and Short, M., "The Generation of Axial Vorticity in SolidPropellant Rocket-Motor Flows," Journal of Fluid Mechanics, Vol. 429, No. 1, Feb. 2001, pp. 283-305. doi: $10.1017 /$ S0022112000002688

[82] Wang, J and Joseph, D.D., Boundary-layer analysis for effects of viscosity of the irrotational flow on the flow induced by a rapidly rotating cylinder in a uniform stream, J. Fluid Mech. (2006), vol. 557, pp. 167-190. doi: 10.1017/S0022112006009670

[83] Anderson, J.D. Jr. Modern Compressible Flow, with Historical Perspective," Fourth Edition, McGrawHill Publishing Company. (2007)

[84] John S. Pellerito and Joseph F. Polak, Introduction to Vascular Ultrasonography, $6^{\text {th }}$ Edn., Elsevier, ISBN: 9781437714173, eBook ISBN: 9780323248303, May 2012.

[85] Menter, F.R., "Two-Equation Eddy-Viscosity Turbulence Models for Engineering Applications," AIAA Journal, Vol. 32, No. 8, pp. 1598-1605, 1994. doi: 10.2514/3.12149

[86] Elaine S.OranVadim N.Gamezo, Origins of the deflagration-to-detonation transition in gas-phase combustion, Combustion and Flame, Volume 148, Issues 1-2, January 2007, Pages 4-47

[87] Li, Q., Kellenberger, M., \& Ciccarelli, G. (2020). Geometric influence on the propagation of the quasidetonations in a stoichiometric H2-02 mixture. Fuel, 269, 117396. doi:10.1016/j.fuel.2020.117396 
[88] He, C., Zhang, J., \& Shreeve, J. M. (2013). Dense lodine-Rich Compounds with Low Detonation Pressures as Biocidal Agents. Chemistry - A European Journal, 19(23), 7503-

7509. doi:10.1002/chem.201300565

[89] Yang, Q., Yang, G., Zhang, W., Zhang, S., Yang, Z., Xie, G., ... Gao, S. (2017). Superior Thermostability, Good Detonation Properties, Insensitivity, and the Effect on the Thermal Decomposition of Ammonium Perchlorate for a New Solvent-Free 3D Energetic Pbll -MOF. Chemistry - A European Journal, 23(38), 9149-9155. doi:10.1002/chem.201701325

[90] Wang, F., Wang, G., Du, H., Zhang, J., \& Gong, X. (2011). Theoretical Studies on the Heats of Formation, Detonation Properties, and Pyrolysis Mechanisms of Energetic Cyclic Nitramines. The Journal of Physical Chemistry A, 115(47), 13858-13864. doi:10.1021/jp2047536

[91] Lu, Y., Zhu, Z., Wu, W., \& Liu, Z. (2002). Detonation chemistry of a CHNO explosive: catalytic assembling of carbon nanotubes at low pressure and temperature state. Chemical Communications, (22), 2740-2741. doi:10.1039/b207166e

[92] Richard L. Li, Jonathan Russ, Costas Paschalides, Giovanni Ferrari, Haim Waisman, Jeffrey W. Kysar, David Kalfa, Mechanical considerations for polymeric heart valve development: Biomechanics, materials, design and manufacturing, Biomaterials, Volume 225, December 2019, 119493, DOI: https://doi.org/10.1016/j.biomaterials.2019.119493

[93] Jiayin Fu, Yingchao Su, Yi-Xian Qin, Yufeng Zheng, Yadong Wang, Donghui Zhu, Evolution of metallic cardiovascular stent materials: A comparative study among stainless steel, magnesium and zinc, Biomaterials, Volume 230, February 2020, 119641, DOI:

https://doi.org/10.1016/j.biomaterials.2019.119641

[94] Adebiyi AA, Taslim ME, Crawford KD., The use of computational fluid dynamic models for the optimization of cell seeding processes, Biomaterials. 2011 Dec;32(34):8753-70. doi:

10.1016/j.biomaterials.2011.08.028. Epub 2011 Aug 31.

[95] Savoji H, Mohammadi MH, Rafatian N, Toroghi MK, Wang EY, Zhao Y, Korolj A, Ahadian S, Radisic $\mathrm{M}$, Cardiovascular disease models: A game changing paradigm in drug discovery and screening, Biomaterials. 2019 Apr;198:3-26. doi: 10.1016/j.biomaterials.2018.09.036. Epub 2018 Oct 1.

[96] Marozas, I. A., Anseth, K. S., \& Cooper-White, J. J. (2019). Adaptable boronate ester hydrogels with tunable viscoelastic spectra to probe timescale dependent mechanotransduction. Biomaterials, 119430. doi:10.1016/j.biomaterials.2019.119430

[97] Välimaa, T., Laaksovirta, S., Tammela, T. L. et al. (2002). Viscoelastic memory and self-expansion of self-reinforced bioabsorbable stents. Biomaterials, 23(17), 3575-3582. doi:10.1016/s0142-

9612(02)00076-5 
[98] H. C Gledhill, I. G Turner, C Doyle, In vitro fatigue behaviour of vacuum plasma and detonation gun sprayed hydroxyapatite coatings, Biomaterials, Volume 22, Issue 111 June 2001Pages 1233-1240

[99] Gledhill, H. C., Turner, I. G., \& Doyle, C. (1999). Direct morphological comparison of vacuum plasma sprayed and detonation gun sprayed hydroxyapatite coatings for orthopaedic applications. Biomaterials, 20(4), 315-322. doi:10.1016/s0142-9612(98)00166-5

[100] Pelaz, B., Alexiou, C., Alvarez-Puebla, R. A., Alves, F., Andrews, A. M., Ashraf, S., ... Brendel, C. (2017). Diverse Applications of Nanomedicine. ACS Nano, 11(3), 23132381. doi:10.1021/acsnano.6b06040

[101] V.R.Sanal Kumar et al., Streamtube Flow-Choking in Nanoscale Systems: An Exact Prediction of the 3D Boundary-Layer-Displacement-Thickness of Diabatic Flows at the Zero-Slip-Length, Nano Today (under editorial review).

[102] Seifert, G. The physics of explosive chemistry. Nature Phys 4, 12-13 (2008). https://doi.org/10.1038/nphys824

[103] M. Moseler and U. Landman, Formation, stability, and breakup of nanojets, Science 289, 1165 (2000).

[104] Chengxi Zhao, Duncan A. Lockerby, and James E. Sprittles, Dynamics of liquid nanothreads: Fluctuation-driven instability and rupture, Phys. Rev. Fluids 5, 044201 - Published 2 April 2020.

[105] Holland, D. M., Borg, M. K., Lockerby, D. A., \& Reese, J. M. (2015). Enhancing nano-scale computational fluid dynamics with molecular pre-simulations: Unsteady problems and design optimisation. Computers \& Fluids, 115, 46- 53. doi:10.1016/j.compfluid.2015.03.023

[106] Singh, H., \& Myong, R. S. (2018). Critical Review of Fluid Flow Physics at Micro- to Nano-scale Porous Media Applications in the Energy Sector. Advances in Materials Science and Engineering, 2018, 1-31. doi:10.1155/2018/9565240

[107] Burrows, A. Supernova explosions in the Universe. Nature 403, 727-733 (2000). https://doi.org/10.1038/35001501

[108] Woosley, S. E., Wunsch, S., Kuhlen, M., Carbon Ignition in Type la Supernovae: An Analytic Model, The Astrophysical Journal, Volume 607, Issue 2, pp. 921-930., June 2004, 10.1086/383530

[109] NEWITT, D. Hydrodynamical Theory of Detonation and Shock Waves. Nature 172, 699 (1953). https://doi.org/10.1038/172699a0 
[110] Creighton, T. An explosion of sound. Nature Phys 2, 581-582 (2006).

https://doi.org/10.1038/nphys387

[111] Reed, E., Riad Manaa, M., Fried, L. et al. A transient semimetallic layer in detonating nitromethane. Nature Phys 4, 72-76 (2008). https://doi.org/10.1038/nphys806

[112] Pasachoff, J., Pasachoff, N. Appointment at Trinity. Nature Phys 1, 74-75 (2005).

https://doi.org/10.1038/nphys165

[113] Koolivand, A., Dimitrakopoulos, P. Deformation of an elastic capsule in a microfluidic T-junction: settling shape and moduli determination. Microfluid Nanofluid 21, 89 (2017). https://doi.org/10.1007/s10404-017-1923-6

[114] Jambon-Puillet, E., Jones, T.J. \& Brun, P. Deformation and bursting of elastic capsules impacting a rigid wall. Nat. Phys. 16, 585-589 (2020). https://doi.org/10.1038/s41567-020-0832-x

[115] Gamezo, V. N., Khokhlov, A. M., Oran, E. S., Chtchelkanova, A. Y. \& Rosenberg, R. O. Thermonuclear supernovae: Simulations of the deflagration stage and their implications. Science 299, 77-81 (2003).

[116] Hillebrandt, W. \& Niemeyer, J. C. Type la supernova explosion models. Annu. Rev. Astron. Astrophys. $38,191-230$ (2000).

[117] Nomoto, K., Iwamoto, K. \& Kishimoto, N. Type la supernovae; their origin and possible applications in cosmology. Science 276, 1378-1382 (1997).

[118] 1. Woosley, S. E. \& Weaver, T. A. The evolution and explosion of massive stars. II. Explosive hydrodynamics and nucleosynthesis. Astrophys. J. Suppl. 101, 181-235 (1995).

[119] Nomoto, K. \& Hashimoto, M. Pre-supernova evolution of massive stars. Phys. Rep. 163, 13-36 (1988).

[120] Woosley, S. E., Eastman, R. G. \& Schmidt, B. P. Gamma-ray bursts and type Ic supernova SN 1998bw. Astrophys. J. 516, 788- 796 (1999).

[121] Chiao, M. Novel observations. Nature Phys 10, 791 (2014). https://doi.org/10.1038/nphys3155

\section{Figures}




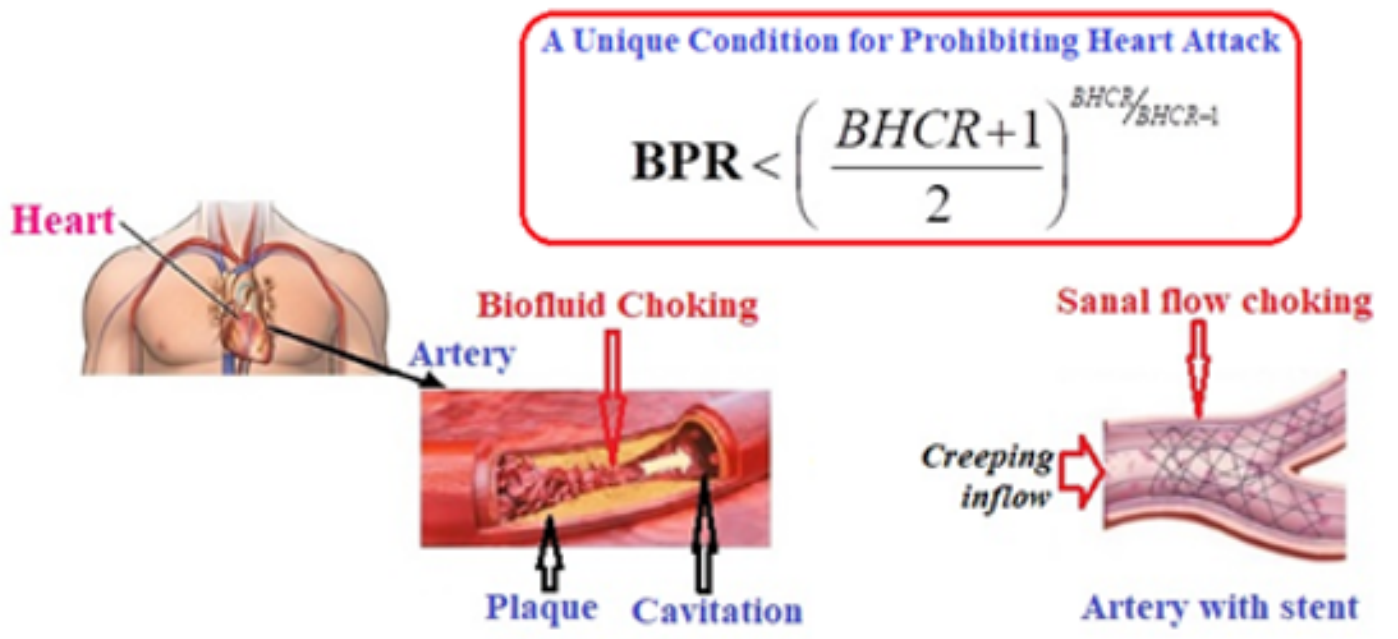

(a) An artery with plaque having the

(e) An artery without plaque and with stent in the bifurcation region shape of a CD nozle flow passage
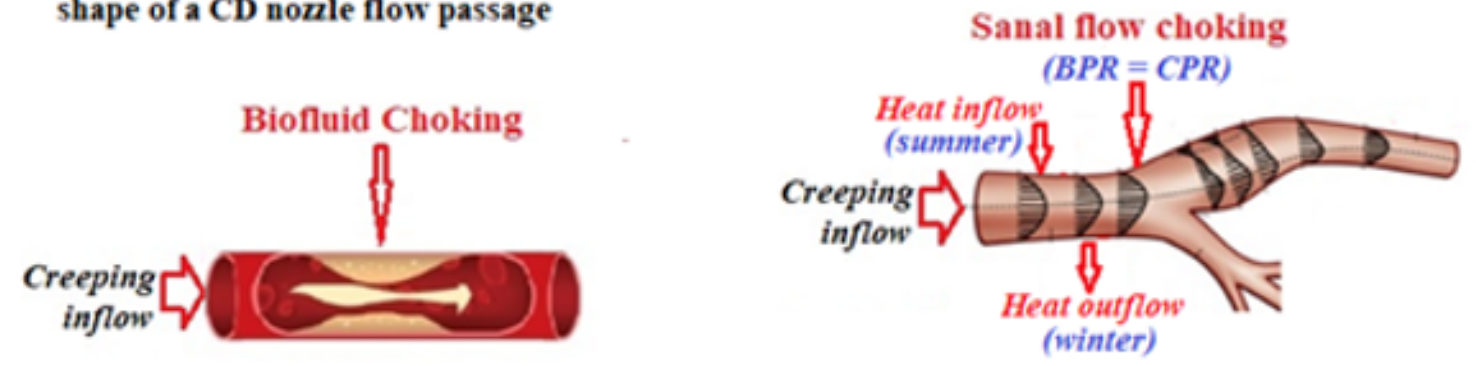

(b) Angina - CD nozle flow effect

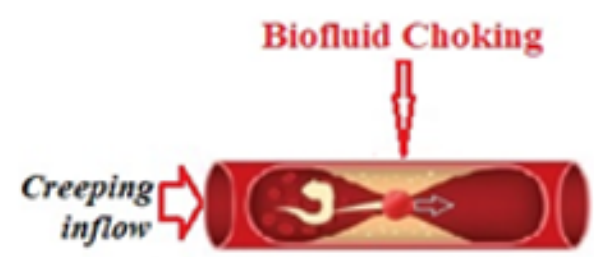

(c) A blocked artery showing CD nozle nanoflow effect

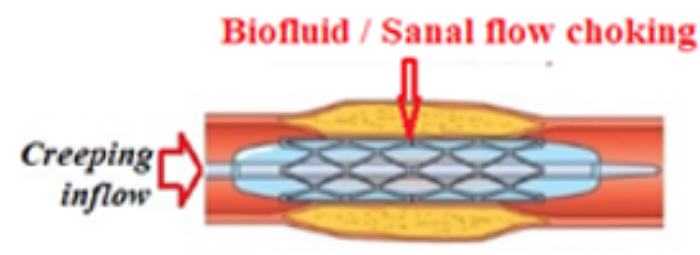

(d) An artery with plaque and stent

(f) A healthy artery with bifurcation and without stent

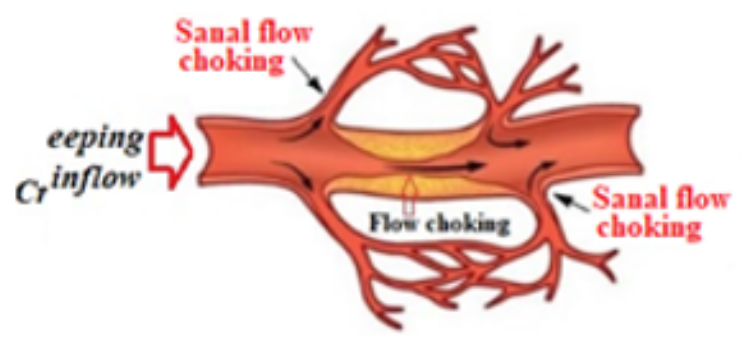

(g) An artery with plaque and collateral circulation

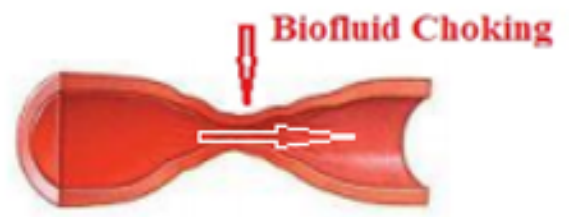

(h) Vasospasm

\section{Figure 1}

Internal flow choking in HCS (The Central Illustration) [1]. 


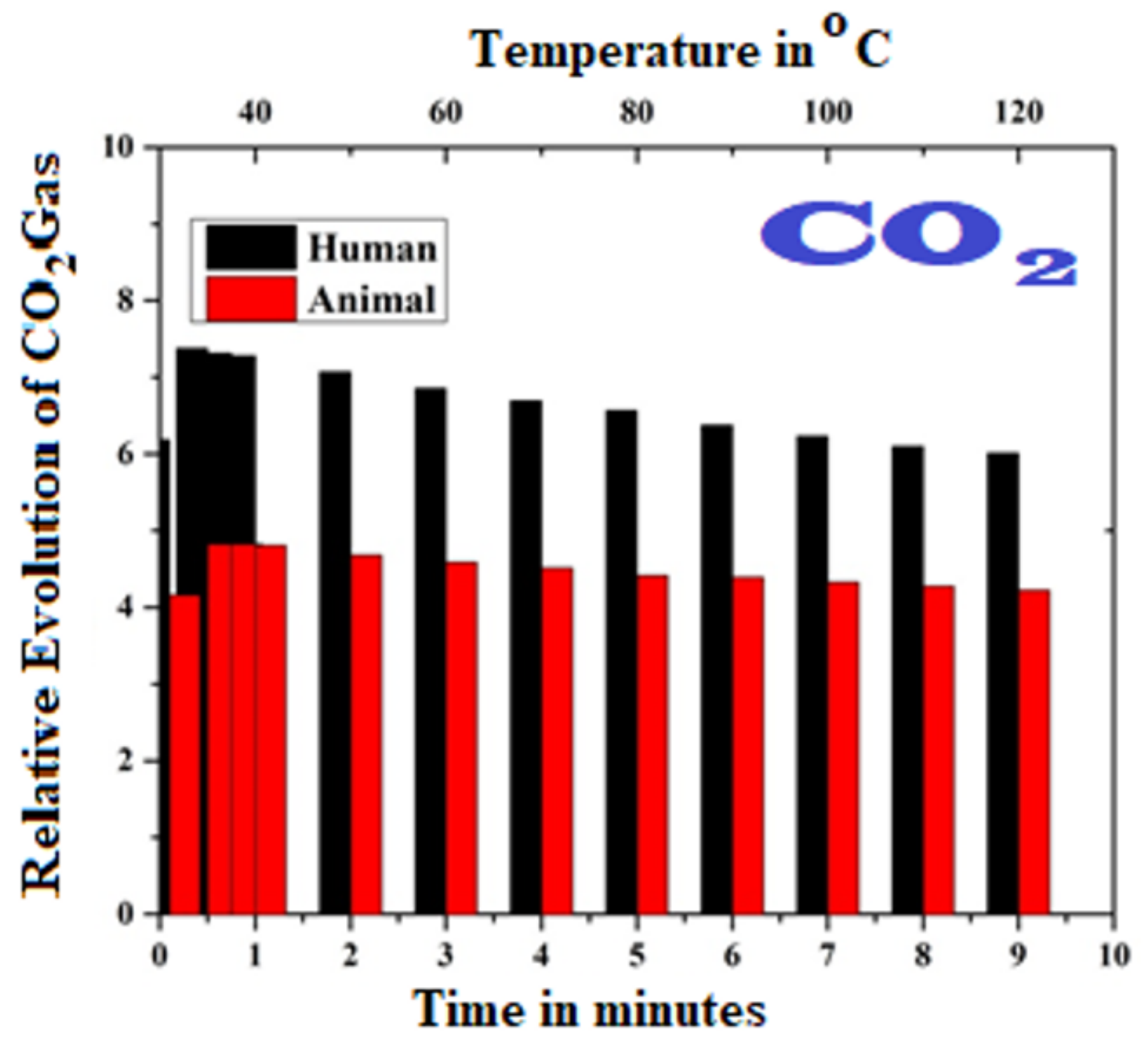

Figure 2

In vitro result shows the mass spectrum of carbon dioxide (CO2) evolved as a function of both time and temperature in blood samples of healthy subjects beyond the physiological range (the human being / Guinea-pig) [5]. 


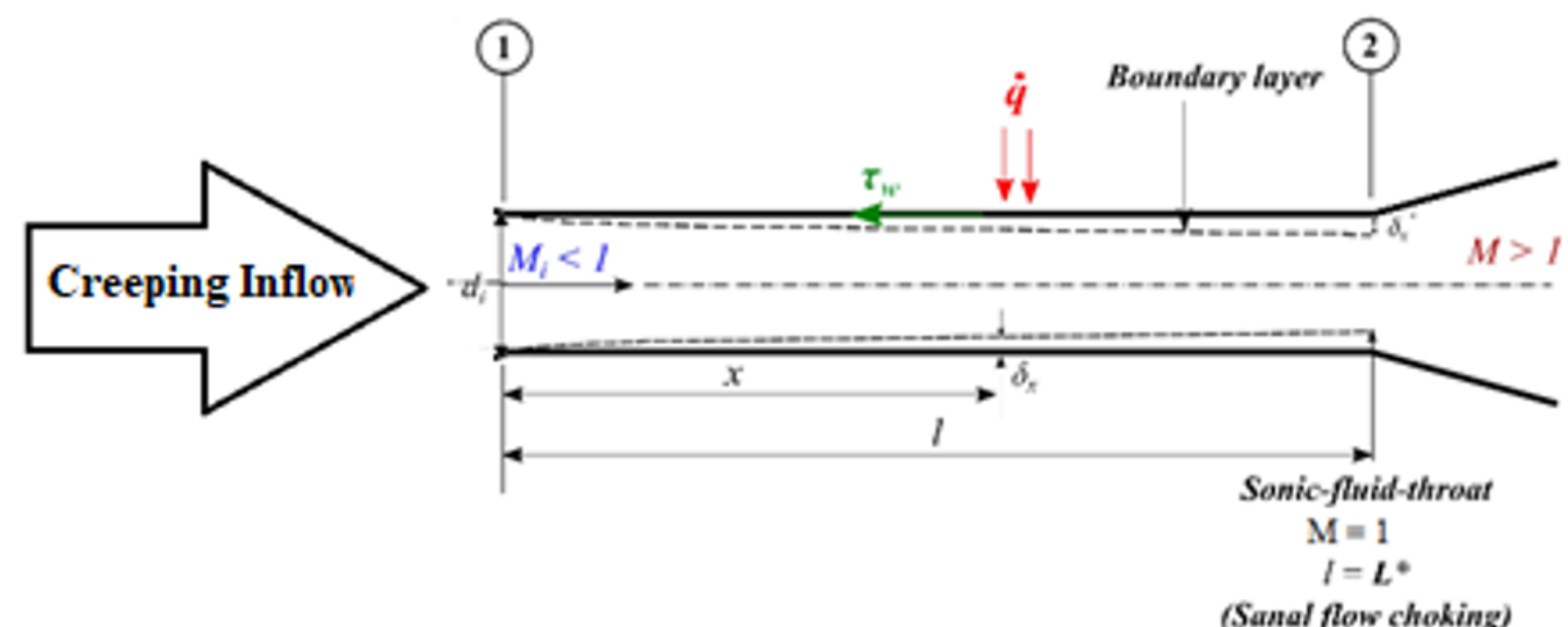

Figure 3

Demonstrating the Sanal flow choking condition in an internal fluid flow system. 

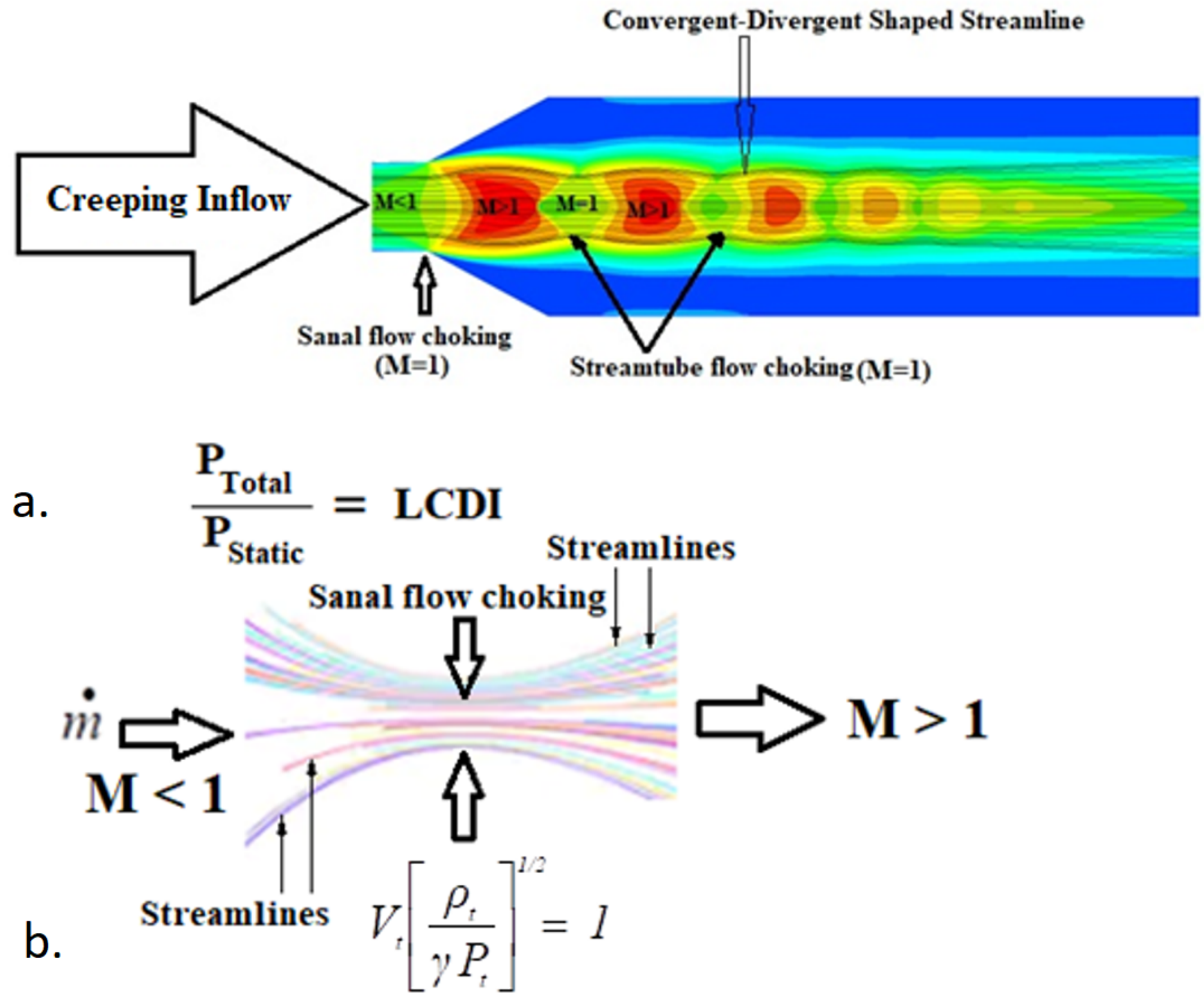

Figure 4

(a). Demonstrating the Sanal flow choking and streamtube flow choking condition in an idealized physical model of an internal fluid flow system.(b). Demonstrating the CD duct flow effect in yocto to yotta scale internal and external flow systems leading to flow choking. 


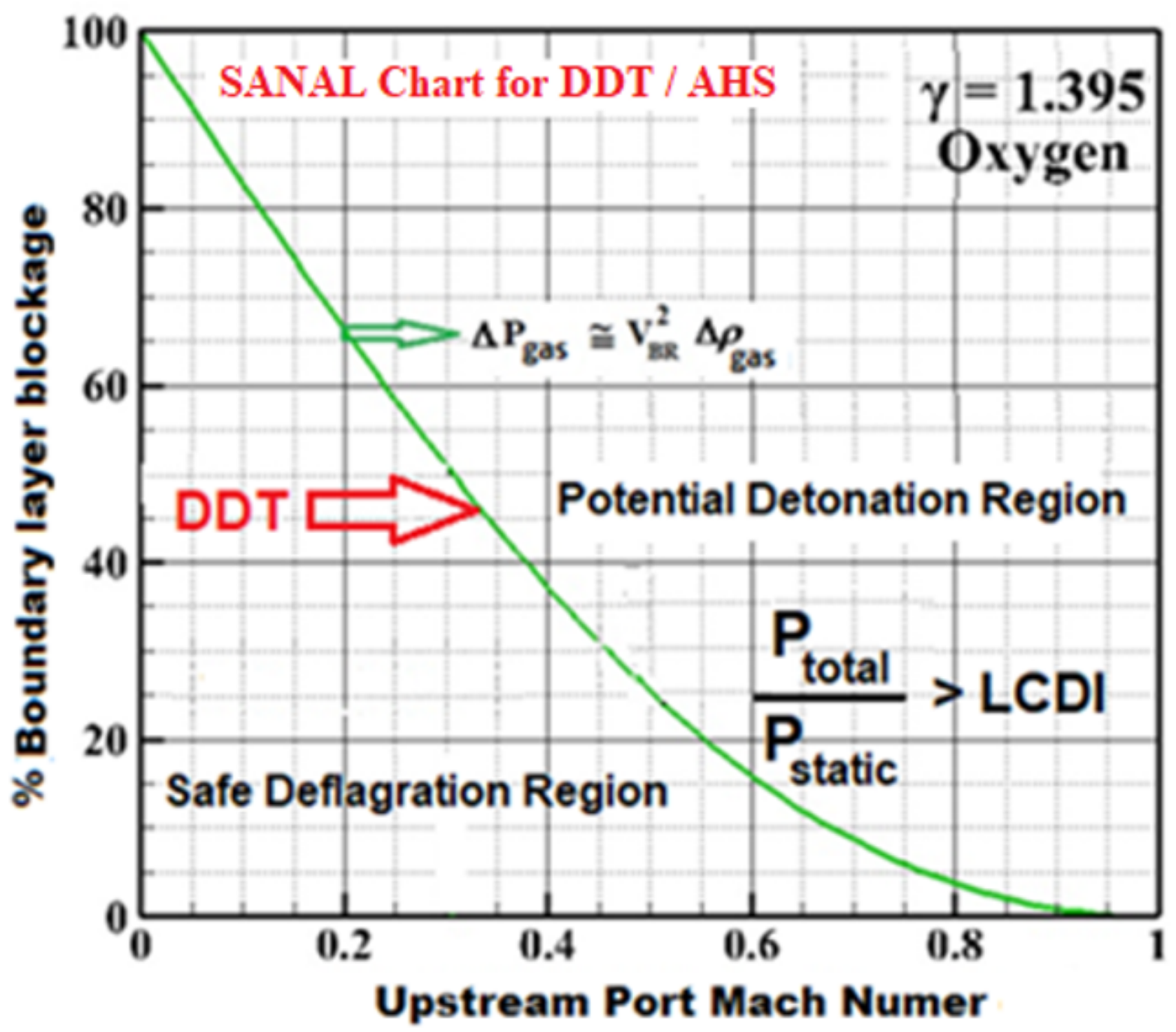

Figure 5

Demonstrating the condition of DDT and AHS in an internal flow system at the Sanal flow choking condition. 

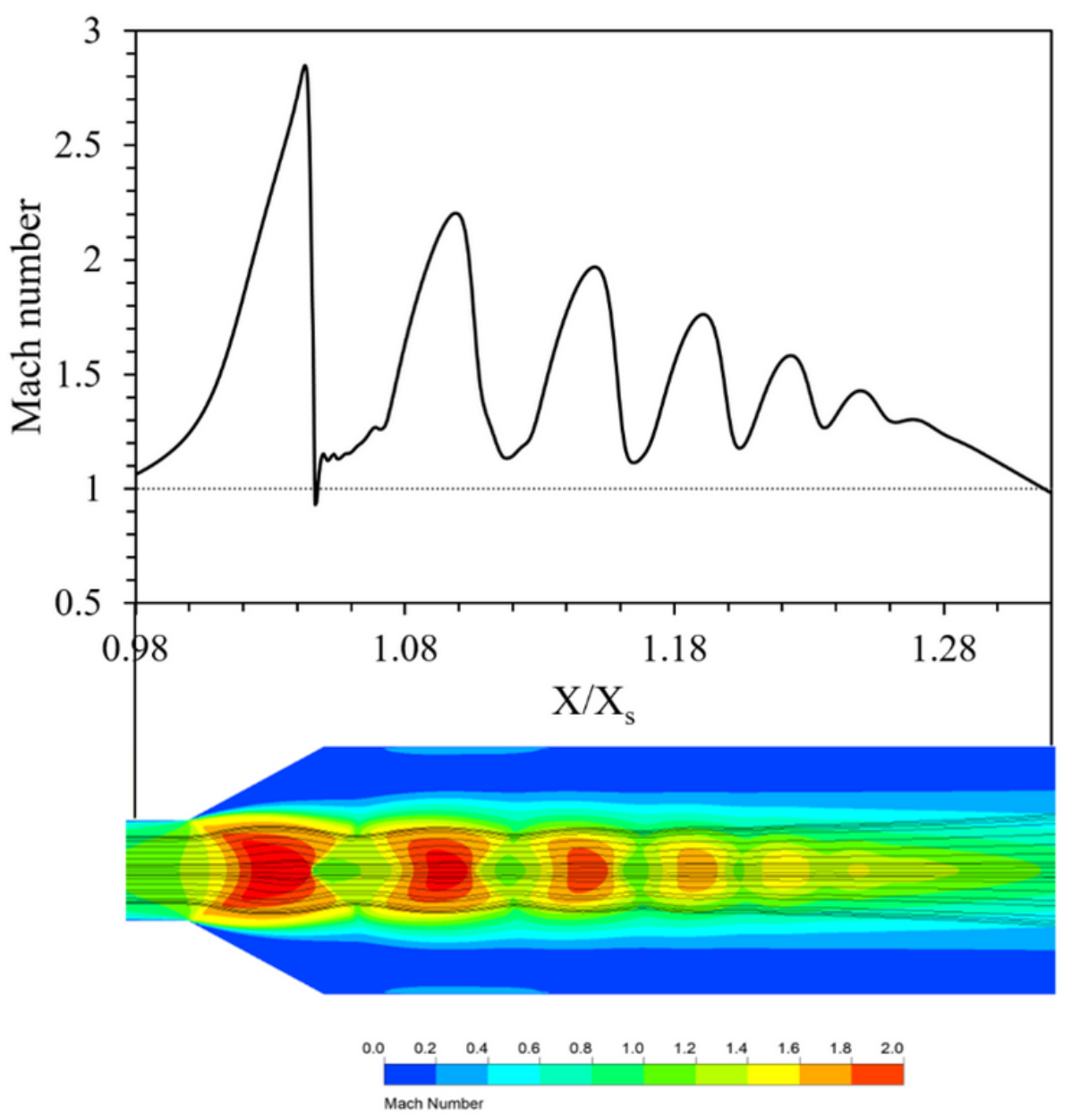

(a)

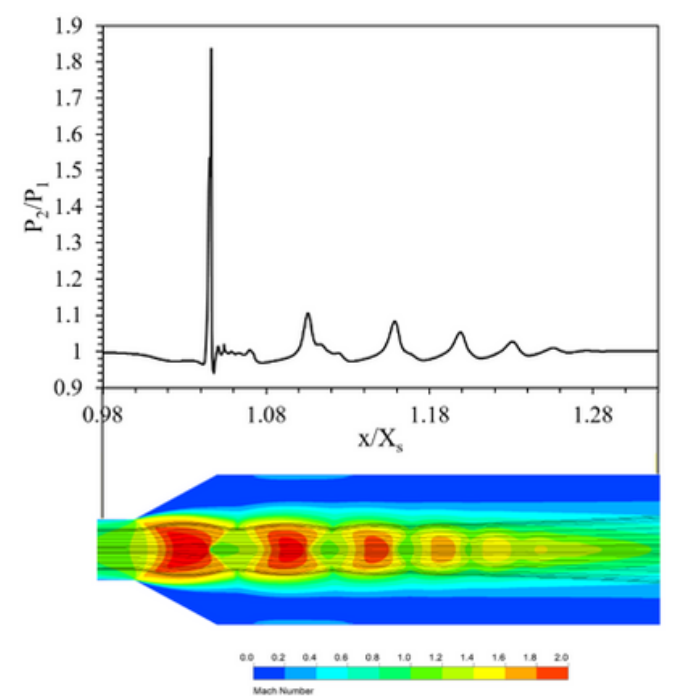

(b)

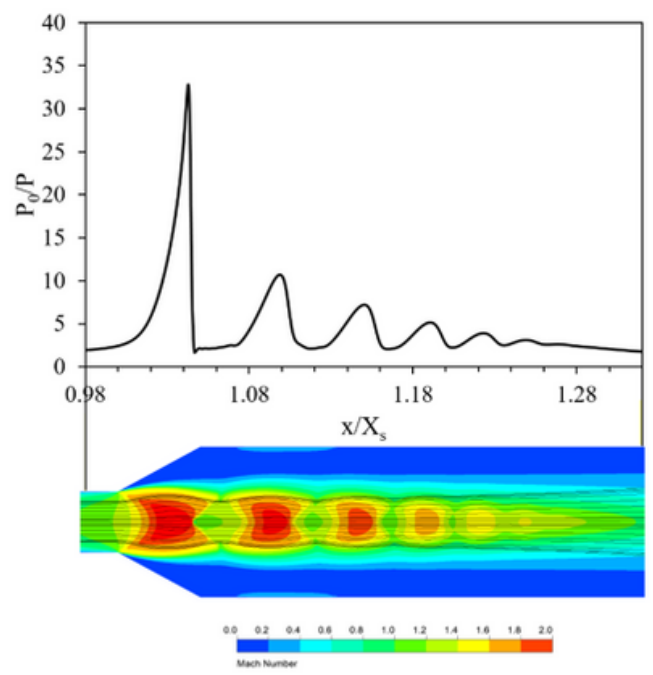

(c)

\section{Figure 6}

Demonstrating the shape of the streamtube, Mach number variations, pressure ratio variation, and the detonation region during the Sanal flow choking condition (enlarged view at $\mathrm{t}=90 \mathrm{~ms}$ ). 

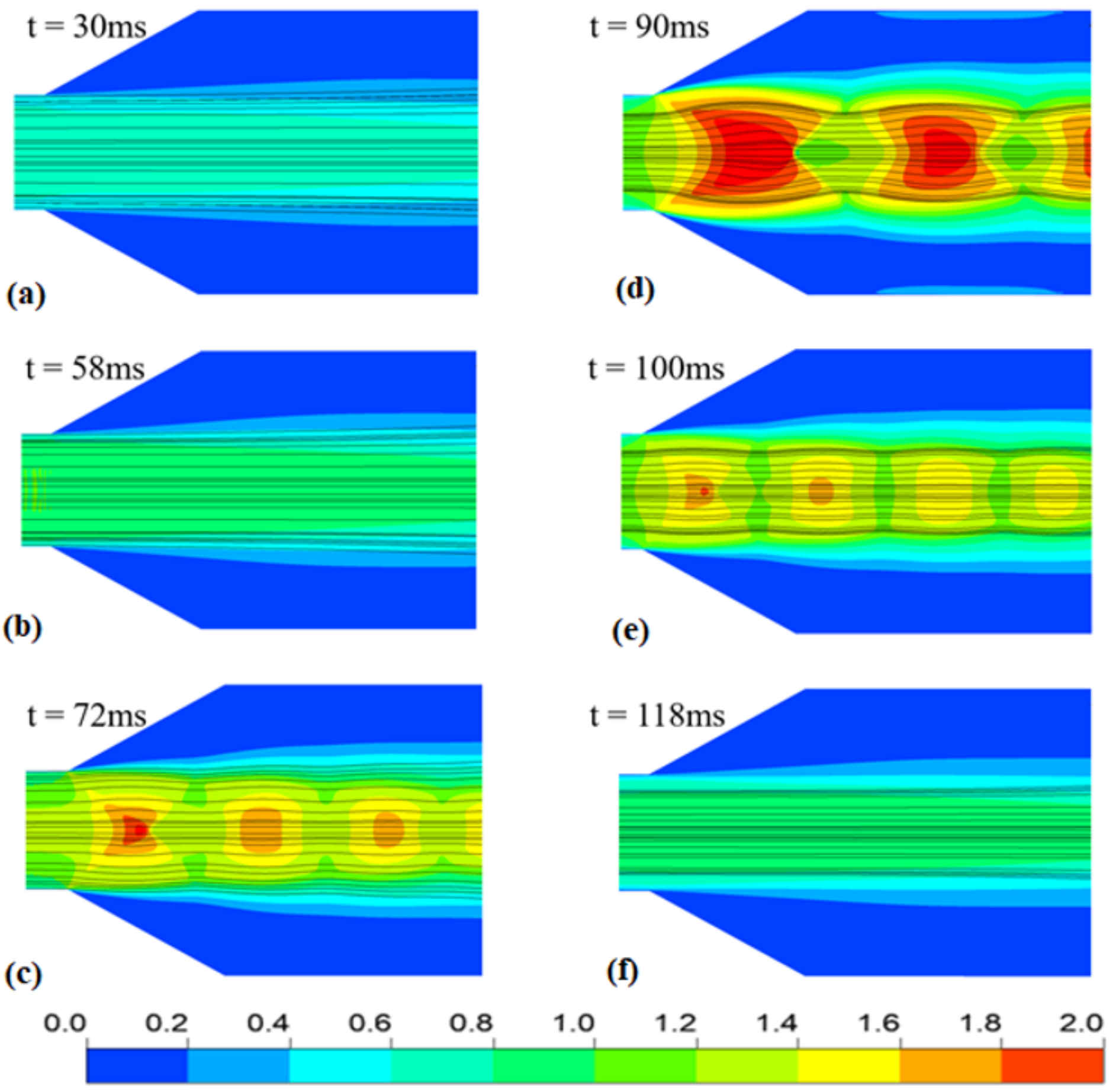

\section{Mach Number}

Figure 7

Demonstrating the shape of the streamtube and the Mach number contours at different time intervals before and after the Sanal flow choking (enlarge view of the transition region). 